\title{
Long term superhydrophobic and hybrid superhydrophobic/superhydrophilic surfaces produced by laser surface micro/nano surface structuring
}

DOI:

10.1016/j.apsusc.2018.10.099

\section{Document Version}

Accepted author manuscript

Link to publication record in Manchester Research Explorer

Citation for published version (APA):

Rajab, F. H., Liu, Z., \& Li, L. (2019). Long term superhydrophobic and hybrid superhydrophobic/superhydrophilic surfaces produced by laser surface micro/nano surface structuring. Applied Surface Science, 466, 808-821. https://doi.org/10.1016/j.apsusc.2018.10.099

Published in:

Applied Surface Science

\section{Citing this paper}

Please note that where the full-text provided on Manchester Research Explorer is the Author Accepted Manuscript or Proof version this may differ from the final Published version. If citing, it is advised that you check and use the publisher's definitive version.

\section{General rights}

Copyright and moral rights for the publications made accessible in the Research Explorer are retained by the authors and/or other copyright owners and it is a condition of accessing publications that users recognise and abide by the legal requirements associated with these rights.

\section{Takedown policy}

If you believe that this document breaches copyright please refer to the University of Manchester's Takedown Procedures [http://man.ac.uk/04Y6Bo] or contact uml.scholarlycommunications@manchester.ac.uk providing relevant details, so we can investigate your claim.

\section{OPEN ACCESS}




\title{
Long term superhydrophobic and hybrid superhydrophobic/superhydrophilic surfaces produced by laser surface micro/nano surface structuring
}

\author{
Fatema H. Rajab ${ }^{1,2}$, Zhu Liu' ${ }^{1,3}$ and Lin $\mathrm{Li}^{1 *}$ \\ ${ }^{1}$ Laser Processing Research Centre, School of Mechanical, Aerospace and Civil Engineering, The \\ University of Manchester, Manchester, M13 9PL, UK \\ ${ }^{2}$ College of Engineering, Al-Nahrain University, Baghdad, Iraq \\ ${ }^{3}$ School of Materials, The University of Manchester, Manchester M13 9PL, UK.
}

Corresponding authors *Lin Li: lin.li@manchester.ac.uk.

Fatema H. Rajab, fatema.rajab@postgrad.manchester.ac.uk, fatemarajab83@gmail.com

\begin{abstract}
Stable superhydrophobic and superhydrophilic surfaces were created using laser surface micro/nano patterning. These were based on periodic 3D micro/nanostructures produced on $316 \mathrm{~L}$ stainless steel over large areas using nanosecond and picosecond laser surface fabrication. The effects of laser processing parameters on controlling the micro-/nano-topographical characteristics of 24 different types of structures were presented. Surface roughness, surface chemical composition and wettability (via water contact angle) of these surfaces were characterised. Aging experiments were carried out for up to 8 months to analyse the durability of the prepared surfaces under three conditions of water (hot, normal and icy). Samples with superhydrophobic characteristics, processed with the ps or ns lasers in air, kept dry (water repellent) for over 8 months when tested in ice water $\left(0^{\circ} \mathrm{C}-4^{\circ} \mathrm{C}\right)$, whilst those stored in hot water $\left(80^{\circ} \mathrm{C}\right)$ or room temperature water could only be kept dry for 3-14 weeks. Samples processed in water had shorter water repellent life and samples processed with the ns laser in air had the longest water repellent periods. The hybrid superhydrophobic and superhydrophobic surfaces had a stability life for water repellent and water spreading of over 6 months.
\end{abstract}

Keywords: Ageing, durability, picosecond, nanosecond, hybrid, texture. 


\section{Introduction}

Wettability plays important roles in our daily life [1]. The wettability is characterised by contact angle measurement using a sessile or a resting drop method [2]. When a liquid droplet comes into contact with the surface, it forms a solid-liquid interface. Depending on the measurement of CAs, four types of wettability have been intensively studied, namely, superhydrophilic with a contact angle $\leq 5^{\circ}$, hydrophilic with contact angle $<90^{\circ}$, hydrophobic with a contact angle $\geq 90^{\circ}$ and superhydrophobic with a water contact angle $\geq 150^{\circ}[2]$. In the past few years, superhydrophobic surfaces and superhydrophilic surfaces have shown potential applications in many fields such as self-cleaning [3] and anti-icing [4], improved heat transfer purposes [2, 5], and drag reduction [2, 6]. Different techniques such as photolithography, moulding and plasma treatment have been used to generate different topographies on surfaces to modify the surface wettability [7]. Laser-surface texturing can be used to produce different topographic structures and has been extensively studied for a range of different applications such as the modification of optical properties, wetting properties and modification of surface properties of bioimplants [8-12].

Inspired by nature, artificial structures with superhydrophobic properties that repel the water have been produced by the use of a laser in one of two ways: changing roughness and structure of materials of low surface energy, or generating micro/nanostructures on hydrophobic substrates [1]. In fact, generating superhydrophobic surfaces requires substrates of low surface tension. If the surface tension is high, as in the case of metal substrates, further treatments are required to stabilise the contact angle [1]. A range of structures with different wettability characteristics were produced using fs, ps and ns lasers. For example, fs laser was used to produce structures of different wettability characteristics on silicon [13-17], PDMS silicone elastomer polymer [18-20], glass silica [21], titanium [22], stainless steel [23-25], Polypropylene polymer [26] and cupper [27, 28]. Picosecond laser was used to generate superhydrophobic structures on stainless steel [29-31], cupper [32], titanium [33] and $\mathrm{Al}_{2} \mathrm{O}_{3}$ [34]. Stainless steel [35, 36], aluminium [34, 37], brass [38] and cupper [38] were textured using ns laser for producing a range of superhydrophobic surfaces. From aforementioned works, it was found that generating superhydrophobic metallic surfaces can be conducted in two ways: either by following the laser treatment with fluoroalkylsilane modification of laser-patterned substrates to reduce any surface tension or by measuring the contact angle after a long period of time (around one month) [1]. However, in the second approach, the contact angle is unstable and the surface can easily lose its wettability due to contamination or high water pressure [1]. For substrates of low surface tension like polymers, the superhydrophobic surfaces are achieved by inducing micro/nanostructures onto their surfaces [1]. It has been reported that the metal surfaces become superhydrophilic directly after laser treatment and the contact angle 
changes over time. Long-term superhydrophilc surfaces was produced using simple one-step method by using laser surface texturing with simultaneous glass deposition.

Despite various studies in laser modification of material surface wettability, little is known on long-term stability of these surfaces and there have been no previous reports on producing hybrid superhydrophobic/superhydrophilic surfaces. This paper work reports the stability of laser generated superhydrophobic surface and a simple and repeatable method is introduced to fabricate hybrid surfaces.

\section{Experimental procedure}

\subsection{Experimental procedure for the investigation of stability of hydrophobic surfaces}

AISI 316L stainless steel sheets with dimensions of $10 \mathrm{~mm} \times 10 \mathrm{~mm} \times 0.7 \mathrm{~mm}$ (length $\times$ width $\times$ thickness) were used in this work. Before the laser processing, the samples were cleaned ultrasonically with acetone followed by ethanol before being washed with de-ionised water (DIW) for 10 minutes. A picosecond laser (EdgeWave, $\mathrm{Nd}$ : $\mathrm{YVO}_{4}$, laser parameters: wavelength $\lambda=1064$ $\mathrm{nm}$, repetition rate $=103 \mathrm{kHz}$, focused beam spot size $\mathrm{D}=125 \mu \mathrm{m}$, and laser fluence $=0.625$ $\mathrm{J} / \mathrm{cm}^{2}$ ) and a nanosecond laser (Laserline Laserval Violino, $\mathrm{Nd}: \mathrm{YVO}_{4}$, laser parameters: wavelength $\lambda=532 \mathrm{~nm}$, repetition rate $=30 \mathrm{kHz}$, focused spot size, $\mathrm{D}=55 \mu \mathrm{m}$, and laser fluence $=9.26 \mathrm{~J} / \mathrm{cm}^{2}$ ) were used to irradiate the stainless steel sheets in a raster scan manner in air or under water to study the effect of scanning speed and scanning passes on micro/nanostructure formation, wettability and the durability of wetting behaviour. The laser beams were directed to a set of x-y galvo scanning mirrors then focused on to the sample by a theta flat field lens with a focal length of $\mathrm{F}=245 \mathrm{~mm}$ in the case of the $\mathrm{ns}$ laser and $330 \mathrm{~mm}$ in the case of the ps laser. The scanning was performed in a parallel line regime, and each scanning was performed with a hatch distance (line to line distance) of $10 \mu \mathrm{m}$, at various scanning speeds and number of scanning passes (Table 1). The experiments were performed in air at atmospheric pressure and under de-ionised water (DIW). Water level was $1 \mathrm{~mm}$ above the sample. 


\section{Table 1}

Laser processing parameters used for inducing different surface textures in air and under water.

\begin{tabular}{|c|c|c|}
\hline Surface & Speed $(\mathbf{m m} / \mathbf{s})$ & pass \\
\hline SS1psa, SS1psw, SS1nsa, SS1nsw & 1000 & 1 \\
\hline SS2psa, SS2psw, SS2nsa, SS2nsw & 500 & 1 \\
\hline SS3psa, SS3psw, SS3nsa, SS3nsw & 50 & 1 \\
\hline SS4psa, SS4psw, SS4nsa, SS4nsw & 10 & 1 \\
\hline SS5psa, SS5psw, SS5nsa, SS5nsw & 500 & 10 \\
\hline SS6psa, SS6psw, SS6nsa, SS6nsw & 50 & 10 \\
\hline
\end{tabular}

After the laser surface structuring, the samples were cleaned ultrasonically with ethanol then compressed air to remove the ablated debris or contamination. For characterising the surface morphology and surface oxygen contents, scanning electron microscopy (Philips XL30 FEGSEM) incorporating dispersive energy analysis by X-ray (EDX) was used. A confocal laser scanning optical microscope (Keyence 3D profiler) (CLM) was used to measure the roughness of the surface.

A water drop sessile method using a contact angle analyser FTA 188 was used to investigate the effects of laser irradiation on the wettability characteristics of the samples. Briefly, the laser treated samples and untreated one (control) were immersed into a $1 \%$ heptadecafluoro-1,1,2,2-tetrahydrodecyl-1-trimethoxysilane $\left(\mathrm{CF}_{3}\left(\mathrm{CF}_{2}\right)_{7}\left(\mathrm{CH}_{2}\right)_{2} \mathrm{Si}\left(\mathrm{OCH}_{3}\right)_{3}\right.$ methanol solution for $2 \mathrm{hrs}$ followed by washing in ethanol and drying in an oven at $80^{\circ} \mathrm{C}$ for 30 minutes $[28,29]$ to reduce the surface tesnsion and eliminate the effect of laser-generated surface chemistry change and focus on studying the effect of surface geometry. Subsequently, $6 \mu 1$ droplets of DIW were allowed to contact the surface, and the average contact angles of three different places were recorded.

The ageing test was conducted under three different water conditions (room temperature, hot water $\left(80^{\circ} \mathrm{C}\right)$ and iced water $\left.\left(0^{\circ} \mathrm{C}-4^{\circ} \mathrm{C}\right)\right)$. The samples were immersed in the water and the ice (Fig. 1), and from time to time; they were removed and checked if they wet or dry. The experiment was continued constantly for 8 months. A regular sample check was done on a weekly basis. 


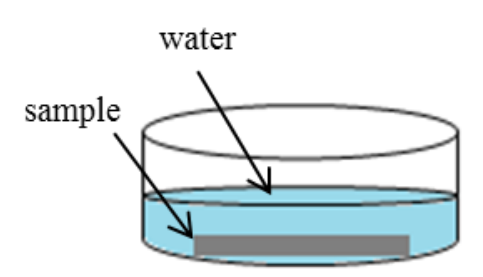

Room temperature

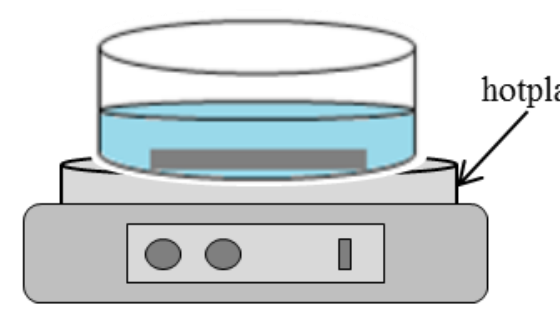

Hot water

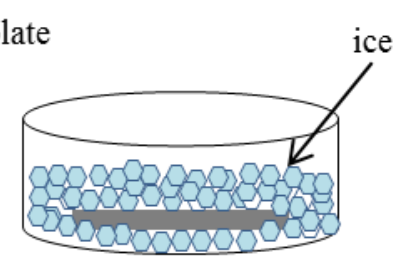

Iced water

Fig. 1. An illustration of aging test under different conditions of water (normal, hot and iced water).

\subsection{Producing hybrid surfaces using laser-surface texturing}

EdgeWave Nd: $\mathrm{YVO}_{4}$ ps and Laserline Laserval Violino, $\mathrm{Nd}: \mathrm{YVO}_{4}$ ns laser were used to pattern the stainless steel with a range of patterns using a two-step processing method. The first step, superhydrophobic areas were produced using laser-surfaces texturing of a stainless steel substrate followed by a salinisation process to reduce the surface tension. Briefly, the samples were immersed into a $1 \%$ heptadecafluoro-1,1,2,2-tetrahydro-decyl-1-trimethoxysilane $\left(\mathrm{CF}_{3}\left(\mathrm{CF}_{2}\right)_{7}\left(\mathrm{CH}_{2}\right)_{2} \mathrm{Si}\left(\mathrm{OCH}_{3}\right)_{3}\right.$ methanol solution for $2 \mathrm{hrs}$ followed by washing in ethanol and drying in an oven at $80^{\circ} \mathrm{C}$ for 30 minutes $[28,29]$. Then, superhydrophilic surfaces were produced using the same procedure presented in our last publication [39]. Briefly, stainless steel substrate was covered with a glass substrate and textured by laser. After the laser processing, the nanostructure and the average contact angle (CA) were measured using Philips XL30 FEG-SEM and FTA 188 contact angle analyser, respectively.

\section{Results and discussion}

\subsection{Aging experiment of hydrophobic surfaces}

Fig.s 2 - 5 show different micro/nano 3D structures generated using the ns and ps laser surface texturing in water and air. It can be seen that the main structure, using the ps laser, was laserinduced periodic surface structures (LIPSS) in air at high scanning speeds of $1000 \mathrm{~mm} / \mathrm{s}$ and 500 $\mathrm{mm} / \mathrm{s}$ (Fig. 2) and in water using low scanning speeds of $50 \mathrm{~mm} / \mathrm{s}, 10 \mathrm{~mm} / \mathrm{s}$ and 10 times (Fig. 3). Using ns laser texturing in the air, the main structure was LIPSS at high scanning speed (1000 $\mathrm{mm} / \mathrm{s}$ and $500 \mathrm{~mm} / \mathrm{s})$ and changed to a cauliflower-like structure at low scanning speed $(50 \mathrm{~mm} / \mathrm{s}$ and $10 \mathrm{~mm} / \mathrm{s}$ ) and high scanning pass (10 passes) (Fig. 4). However, in the case of ns lasertexturing surface in water, the melting process was the dominant and irregular structures were produced on the surface (Fig. 5).

For SS1psa, produced via ps laser texturing in air using high scanning speed $(1000 \mathrm{~mm} / \mathrm{s})$, the periodicity of the produced ripples (LIPSS) was $0.54 \pm 0.09 \mu \mathrm{m}$. However, the main structure of 
SS1psw surface produced using the ps texturing in water was nano-protrusions covered with nanoparticles with diameters of $10-150 \mathrm{~nm}$ and nano-rims of $40 \pm 10 \mathrm{~nm}$. With decreasing the scanning speed to $500 \mathrm{~mm} / \mathrm{s}$ (SS2psa), the periodicity of the ripples formed in the air was slightly increased to $0.8 \pm 0.2 \mu \mathrm{m}$ compared with SS1psa. Moreover, there were holes of $0.44 \pm 0.12 \mu \mathrm{m}$ in diameter distributed irregularly among the surface. In water, irregular ripples with a periodicity of $0.3 \pm 0.1 \mu \mathrm{m}$ started to be obvious (SS2psw). There were also protrusions of $24-69 \mathrm{~nm}$ and rims-like structures of 50-160 $\mathrm{nm}$ in size. The size of rims and protrusions in case of SS2psw were also bigger than that formed using a higher scanning speed $1000 \mathrm{~mm} / \mathrm{s}$ (SS1psw) in water. With further decreasing the scanning speed to $50 \mathrm{~mm} / \mathrm{s}$ (SS3psa) and increasing the scanning passes to 10 (SS5psa), in the air, the ripples were broken with holes which were in the direction perpendicular to the ripples direction. The ripples periodicity / holes diameters in case of SS3psa and SS5psa were $1.4 \pm 0.3 \mu \mathrm{m} / 1.1 \pm 0.2 \mu \mathrm{m}$ and $1.2 \pm 0.2 \mu \mathrm{m} / 0.9 \pm 0.1 \mu \mathrm{m}$, respectively. A conical like structure was formed at a scanning speed of $10 \mathrm{~mm} / \mathrm{s}$ (SS4psa). The width of these cones was $5.6 \pm 1.3 \mu \mathrm{m}$. The width of the microgrooves between the cones was $0.8 \pm 0.34 \mu \mathrm{m}$. LIPSS of $1.53 \pm 0.2 \mu \mathrm{m}$ periodicity and grooves of $1 \pm 0.2 \mu \mathrm{m}$ width sizes were formed using 50 $\mathrm{mm} / \mathrm{s}$ with 10 scanning pass (SS6psa). There were some small particles covered SS3psa, SS4psa and SS6psa. These particles were of size $0.2 \pm 0.1 \mu \mathrm{m}, 0.1 \pm 0.09 \mu \mathrm{m}$, and $0.13 \pm 0.08 \mu \mathrm{m}$, respectively, in case of SS3psa, SS4psa and SS6psa. In water, ripples periodicity of LIPSS formed in case of SS3psw, SS4psw, SS5psw and SS6psw, was $0.3 \pm 0.2 \mu \mathrm{m}, 0.26 \pm 0.09 \mu \mathrm{m}$, and $0.25 \pm$ $0.06 \mu \mathrm{m}$, respectively.
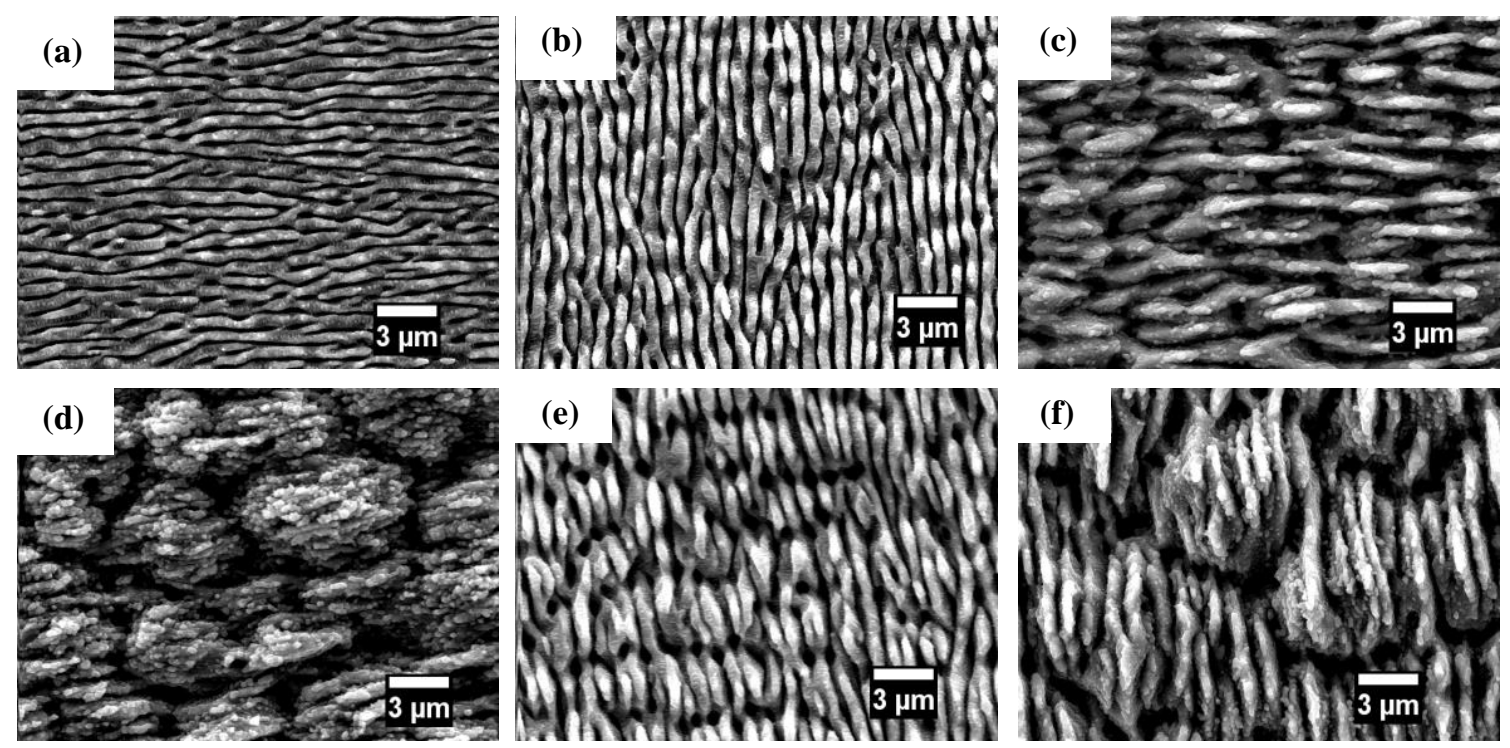

Fig. 2. SEM images of nanostructures generated using ps laser-texturing of 316L SS surface in air. (a) SS1psa, (b) SS2psa, (c) SS3psa, (d) SS4psa, (e) SS5psa and (f) SS6psa. 

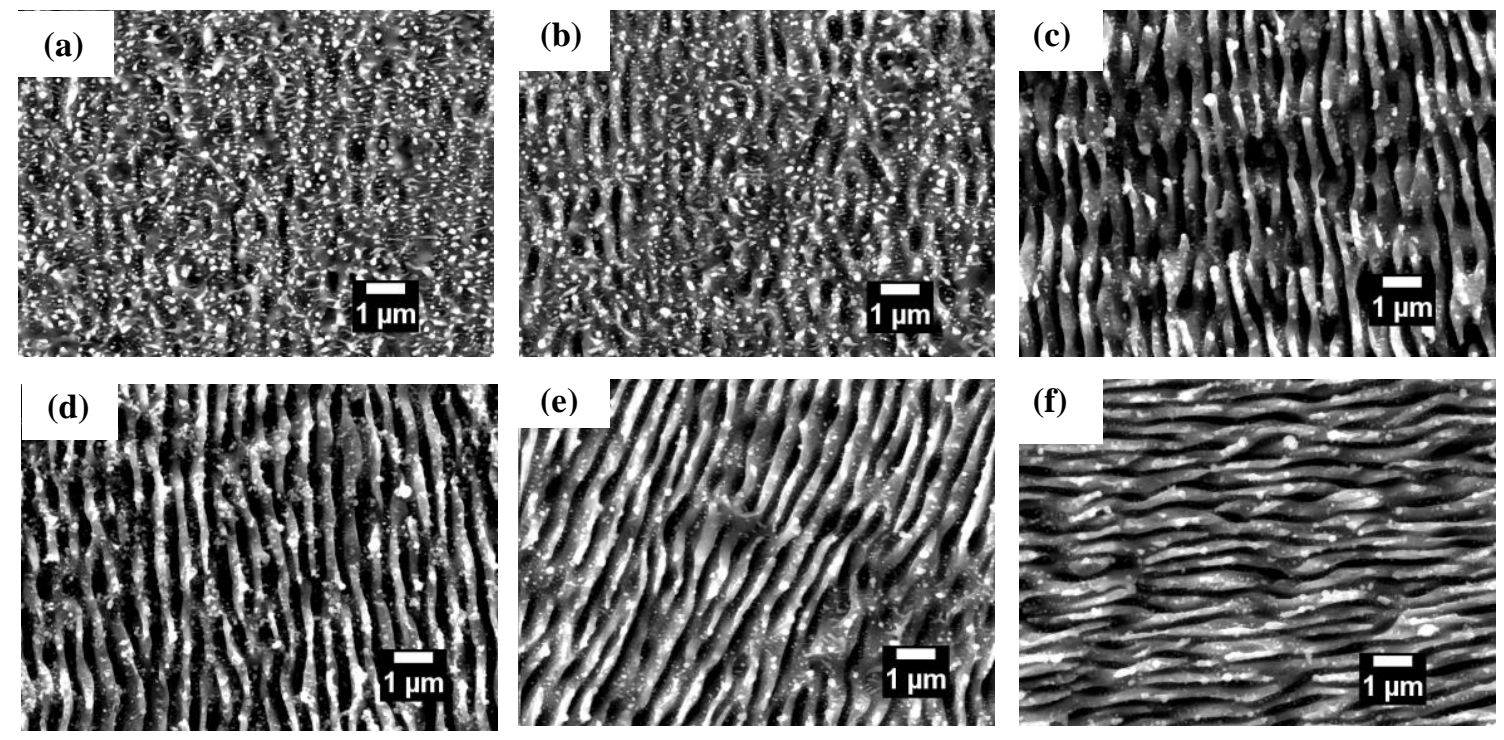

Fig. 3. SEM images of nanostructures generated using ps laser-texturing of 316L SS surface in water. (a) SS1psw, (b) SS2psw, (c) SS3psw, (d) SS4psw, (e) SS5psw and (f) SS6psw.

The ns laser surface texturing in the air produces micro ripples of periodicity $10.2 \pm 1.9 \mu \mathrm{m}$ using $1000 \mathrm{~mm} / \mathrm{s}$ (SS1nsa), and with decreasing scanning speed, different nanostructures were developed (Fig. 4). At a $500 \mathrm{~mm} / \mathrm{s}$ scanning speed, the periodicity of ripples formed was slightly higher than that achieved using $1000 \mathrm{~mm} / \mathrm{s}$ and it was $10.6 \pm 0.8 \mu \mathrm{m}$ (SS2nsa). Using a very small hatch distance $(10 \mu \mathrm{m})$ with a low scanning speed $(50 \mathrm{~mm} / \mathrm{s}$ and $10 \mathrm{~mm} / \mathrm{s})(\mathrm{SS} 3 \mathrm{nsa}$ and SS4nsa) / high scanning pass (10 passes) (SS6nsa), the nanostructure in the air was a cauliflower-like structure. The periodicity of ripples formed in case of $500 \mathrm{~mm} / \mathrm{s}$ and 10 passes (SS5nsa) was of $12.3 \pm 2.5 \mu \mathrm{m}$. The periodicity of the ripples was increased with decreasing the scanning speeds and increasing the scanning times. Then with further decreasing the scanning speed and increasing scanning times, these ripples changed to different nanostructures (SS6nsa). In water (Fig. 5), it can be seen that the resulted structure was characterised as protrusions with the size of $0.8 \pm 0.2 \mu \mathrm{m}$ with some porous structures of $0.2 \pm 0.1 \mu \mathrm{m}$ size at the $1000 \mathrm{~mm} / \mathrm{s}$ scanning speed (SS1nsw). With decreasing the scanning speed to $500 \mathrm{~mm} / \mathrm{s}$ (SS2nsw) and $50 \mathrm{~mm} / \mathrm{s}$ (SS3nsw), the size of protrusion / pores was decreased to $1.2 \pm 0.4 \mu \mathrm{m} / 0.35 \pm 0.2 \mu \mathrm{m}$ and $2.1 \pm 0.8 \mu \mathrm{m} / 0.73 \pm 0.4 \mu \mathrm{m}$, respectively. By further decreasing the scanning speed to $10 \mathrm{~mm} / \mathrm{s}$ (SS4nsw) / increasing passes times (SS6nsw), cones of $7 \pm 1.4 \mu \mathrm{m}(\mathrm{SS} 4 \mathrm{nsw}) / 9.2 \pm 2.1 \mu \mathrm{m}$ (SS6nsw) were induced. Irregular rough surface with holes of $0.23 \pm 0.06 \mu \mathrm{m}$ was also induced. 

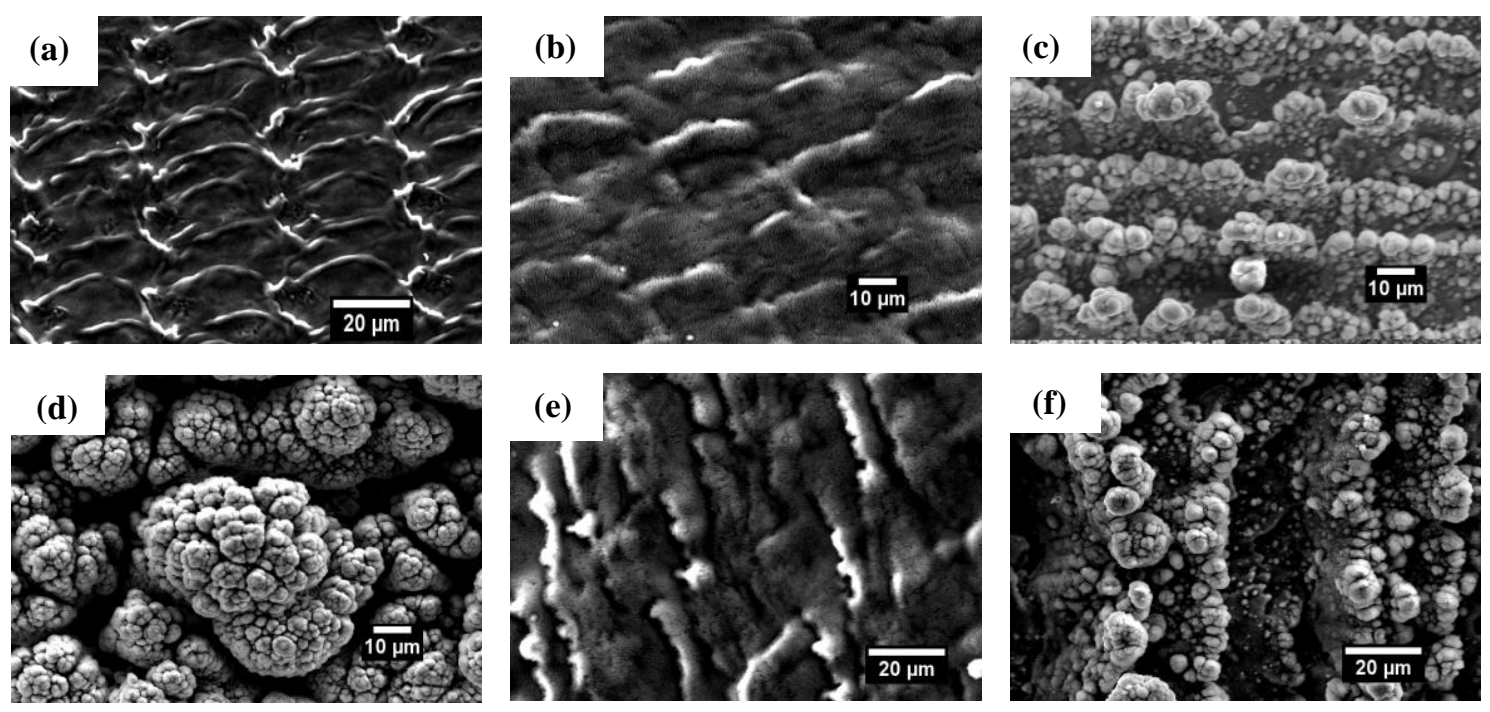

Fig. 4. SEM images of nanostructures generated using ns laser-texturing of 316L SS surface in air. (a) SS1nsa, (b) SS2nsa, (c) SS3nsa, (d) SS4nsa, (e) SS5nsa and (f) SS6nsa.
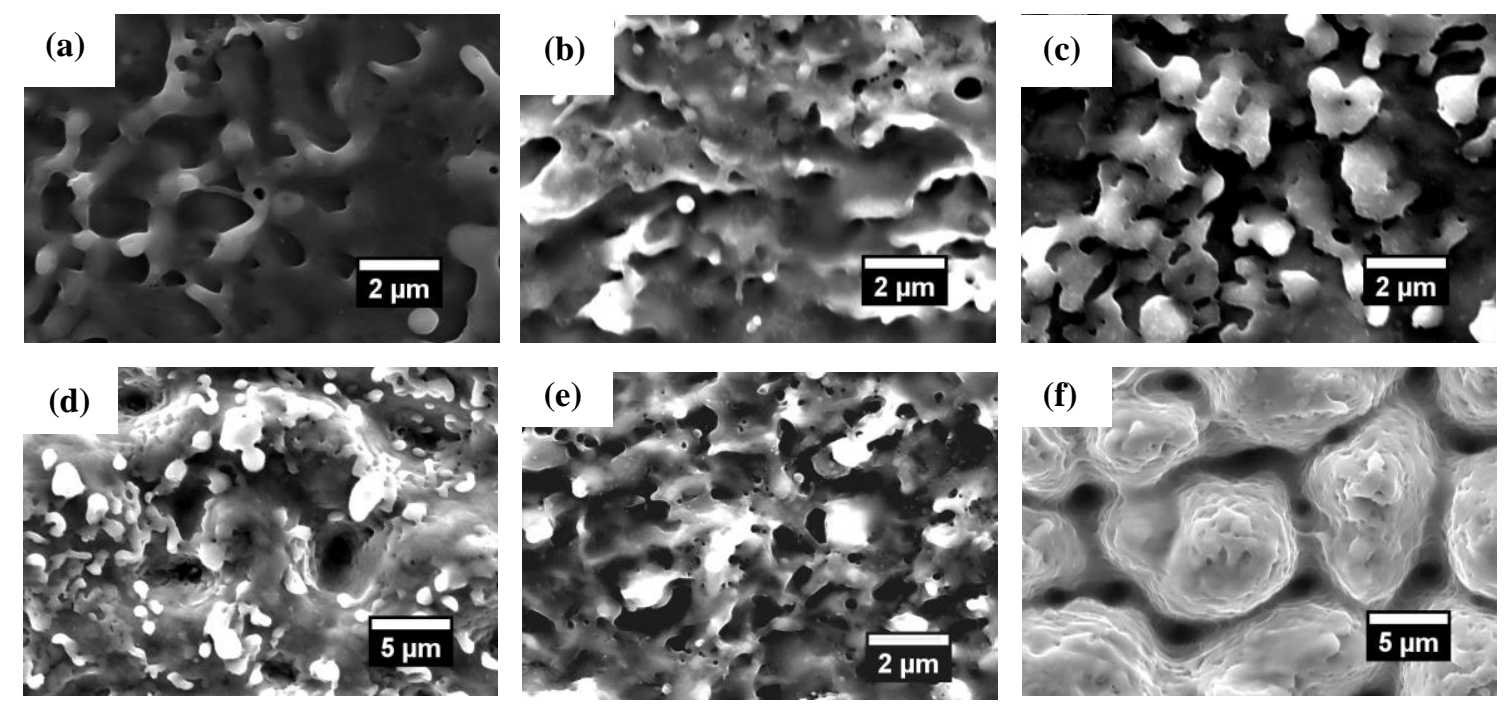

Fig. 5. SEM images of nanostructures generated using ns laser-texturing of 316L SS surface in water. (a) SS1nsw, (b) SS2nsw, (c) SS3nsw, (d) SS4nsw, (e) SS5nsw and (f) SS6nsw.

The change of surface roughness of laser treated surfaces is shown in Fig. 6. It is apparent that the surface roughness of surfaces prepared in the air was higher than those prepared in water. The roughness values of surfaces treated using ns laser were higher than the roughness values of surfaces treated using ps laser. The results showed that SS1 that was prepared at high scanning speed $(1000 \mathrm{~mm} / \mathrm{s})$ and one scanning pass presented lower roughness value among all the other tested surfaces. The roughness was $0.08 \mu \mathrm{m}, 0.05 \mu \mathrm{m}, 0.12 \mu \mathrm{m}$ and $0.16 \mu \mathrm{m}$ in case of SS1ps, SS1psw, SS1nsa and SS1nsw, respectively. Conversely, SS6 had higher roughness value with an $R_{a}$ value of $0.72 \mu \mathrm{m}$ and $0.35 \mu \mathrm{m}$ for (SS6psa) and (SS6psw), respectively, whereas SS4 had higher roughness values with the $R_{a}$ values of $7.1 \mu \mathrm{m}$ and $0.83 \mu \mathrm{m}$ in case of (SS4nsa) and (SS4nsw), respectively. No significant difference was noticed between SS2 and SS1 in surface roughness. 
Moreover, no obvious difference was seen in $R_{a}$ values for SS3 and SS5. The $R_{a}$ values of SS3psa / SS5psa, SS3psw / SS5psw and SS3nsw / SS5nsw were $(0.21 \mu \mathrm{m} / 018 \mu \mathrm{m}, 0.17 \mu \mathrm{m} / 0.019 \mu \mathrm{m}$ and $0.4 \mu \mathrm{m} / 0.3 \mu \mathrm{m})$, respectively.

The surface roughness of SS before laser treatment was measured using CLM and it was $0.02 \mu \mathrm{m}$. The surface roughness of all surfaces increased after the laser treatment. The changes in surface roughness and surface morphology were related to the change of the scanning speed and scanning times altering the number of pulses and overlapps of the pulses which in turns affected the final surface morphology and surface roughness. In this work, using the ns laser, the number of pulses delivered to each location was calculated to be 2, 3, 33,165, 33 and 330 for the respectivce substrates: SS1, SS2, SS3, SS4, SS5 and SS6. Using the ps laser, the number of pulses was 13, 26, 258, 1288, 258 and 2575 for the respectivce substrates: SS1, SS2, SS3, SS4, SS5 and SS6. The pulse overlapping increased from $39 \%$ to $99.9 \%$ by decreasing the scanning speed from 1000 $\mathrm{mm} / \mathrm{s}$ to $10 \mathrm{~mm} / \mathrm{s}$ (ns laser), and the pulse overlapping increased from $92 \%$ to $99.9 \%$ by decreasing the scanning speed from $1000 \mathrm{~mm} / \mathrm{s}$ to $10 \mathrm{~mm} / \mathrm{s}$ (ps laser). Line overlapping, on the other hand, was $81.8 \%$ (for the ns laser) and $92 \%$ (for the ps laser). The difference in pulse and line overlapping between the ns laser and the ps laser processing can be related to the change of spot size and the used repetition rate. The focused spot size of the ns laser was $55 \mu \mathrm{m}$, while that was $125 \mu \mathrm{m}$ for the ps laser; note that the applied hatch distance was $10 \mu \mathrm{m}$ for both lasers.

In air, the mechanism of ns laser interaction with the focal metal to modify the surface was a thermal process where the laser energy was initially absorbed by the surface resulting in rapid increase of surface temperature then melting. At the highest laser fluence, the surface would be vaporised, and plasma would form. This plasma would continue to expand toward the laser beam and shockwaves could be formed as a result of a compression of the surrounding environment ahead of plasma expansion [40]. Ablation is determined by both evaporation and melt expulsion. It depends on pulse duration and pulse energy wherein the ablation mechanism is dominant [40]. In this work, it is clear from Fig. 4 that, at a high scanning speed $(1000 \mathrm{~mm} / \mathrm{s})(\mathrm{SS} 1 \mathrm{nsa})$, the main mechanism was melting then with decreasing the scanning speed (SS2nsa, SS3nsa and SS4nsa) redeposition and condensation of energy on the surface together with the rapid solidification of the molten material took place. The ablated particles solidified around the path of laser forming different structures with different surface roughness [41]. However, at low scanning speeds / scanning times, the number of melted materials was high enough to connect together and forming multi-scale structure such as the cauliflower-like structure (SS4nsa and SS6nsa). In water, the generated surfaces were smooth and of low roughness. Furthermore, it can also be said that melting was the dominated mechanism of ns laser surface texturing in water. However, at the low scanning 
speed and a high number of scanning passes, holes smaller than the laser spot size were noticed on the laser-treated areas indicating the formation of recoil pressure and shockwaves (SS4nsw and SS6nsw). For the ps laser interaction with the material, as the material could evaporate continuously but was transfered into a state of overheated liquid due to the short interaction time, this lead to a high-pressure mixture of liquid droplets and vapour expanding rapidly to end later with a phase explosion at high laser density [40]. In the current work, different topographies were achieved by manipulating the laser processing parameters. The first geometry included nanostructures such as rims, ripples, and protrusions at the high speed of ps laser texturing of SS in air (SS1psa and SS2psa) and all the surfaces (SS1psw, SS2psw, SS3psw, SS4psw, SS5psw and SS6psw) generated at ps laser surface texturing SS in water. It is well known that the formation of these structures can be expected at either low fluences or high fluences with high scanning speeds [23]. The interference of incident and scattered laser irradiation or excited surface waves would be the main mechanism of the formation of the above-mentioned periodic surface structures such as LIPSS [23]. Using low scanning speeds to treat the substrates (SS3psa and SS5psa), some holes were clearer. The formation of these holes might be attributed to the rapid cooling and the solidification of overheated liquid expulsion [40,42]. Using very low scanning speeds / scanning times (SS4psa and SS6psa), dual micro/nanoscale structures were achieved. The formation of these structures was related to the high number of pulses applied per spot resulting in a considerable high amount of laser energy that deposited in a specific small surface area. The roughness of the surface was changed following the first pulse, and the beam absorption was enhanced due to increasing the surface roughness. Then local overheating of the material might have occurred in addition to material ablation, enhanced material melting could potentially take place. Furthermore, the sub-micron particles covered the micron features as a result of sintering the ablated particles together to form these sub-micron features [43]. The surfaces generated in water were almost uniformly modified and that was free from redeposited particles. This might be related to the removal of ablated derbies and nanoparticles away due to the thermal convection of liquid or with the liquid movement $[29,35,44]$. 

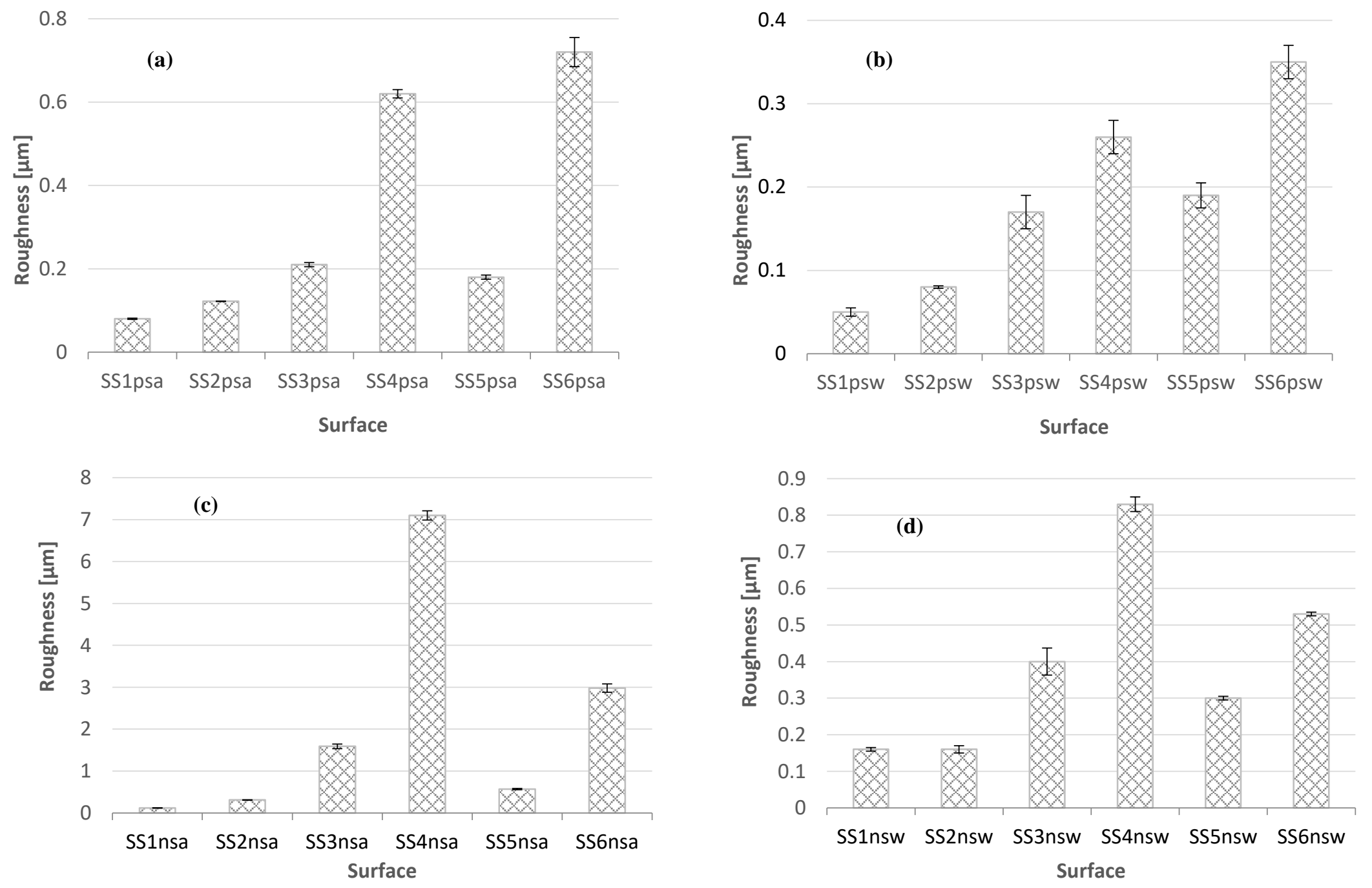

Fig. 6. Surface roughness values of laser-textured surfaces using (a) ps in air, (b) ps in water, (c) ns in air and (d) ns in water. 
The water contact angles of stainless steel surfaces with reducing the surface energy by the chemical treatment and without the laser treatment was measured and found to be as $90.19^{\circ} \pm$ $4.38^{\circ}$. The contact angles of the laser-treated surfaces are shown in Fig. 7. It is clear that the contact angles of the laser-treated surfaces in air were higher than the contact angles of surfaces treated in water. SS1 recorded the lowest contact angles in all cases (psa, psw, nsa and nsw) including the other substrates. Generally, the average contact angles of the surfaces treated using the ps laser were higher than those of the surfaces treated using the ns laser. The higher contact angles of the surfaces treated using the ps laser in air were $160^{\circ}$, while the smallest average contacts angle of the surfaces treated using the ps in air were $133^{\circ}$. Regarding the surfaces treated using the ps laser in water, the highest contact angles was slightly lower than that recorded in air, and it was $150^{\circ}$, and the smallest contact angle was $118^{\circ}$. For the surfaces treated using the ns laser in air, the maximum $\mathrm{CA}$ was $153^{\circ}$, and the lowest $\mathrm{CA}$ was $131^{\circ}$. For the surface treated using ns in water, the maximum $\mathrm{CA}$ was $113^{\circ}$, and the lowest $\mathrm{CA}$ was $94^{\circ}$. The smaller contact angle was noticed in case of SS1. SS4 recorded the highest contact angle. As the values of the contact angle of SS4psa and SS4nsa were higher than $150^{\circ}$, the surfaces can be characterised as superhydrophobic. Moreover, it can be noticed that for the first 4 surfaces (SS1, SS2, SS3 and SS4) in all cases (psa, psw, nsa and nsw), the average contact angle was increased by moving from SS1 to SS4 in all cases, while SS6 witnessed higher contact angle, comparative with SS1, SS2, SS3 and SS5. By linking these findings with the results of the surface roughness (Fig. 6), it is clear that the surface roughness also increased by moving from SS1 to SS4; note thatSS6 was of higher roughness compared with SS1, SS2, SS3 and SS5. The surface of higher roughness was of higher contact angle. Thus, with increasing the surface roughness, increasing the contact angle might be related to increasing the air pocket trapped between the surface features. This behaviour can be explained by the Cassie state because the surfaces may have a large roughness consisting of nanostructures combined with sub-micron and nanostructures with air layer interfac. this layer of air was trapped between features preventing wetting of surface [45]. 

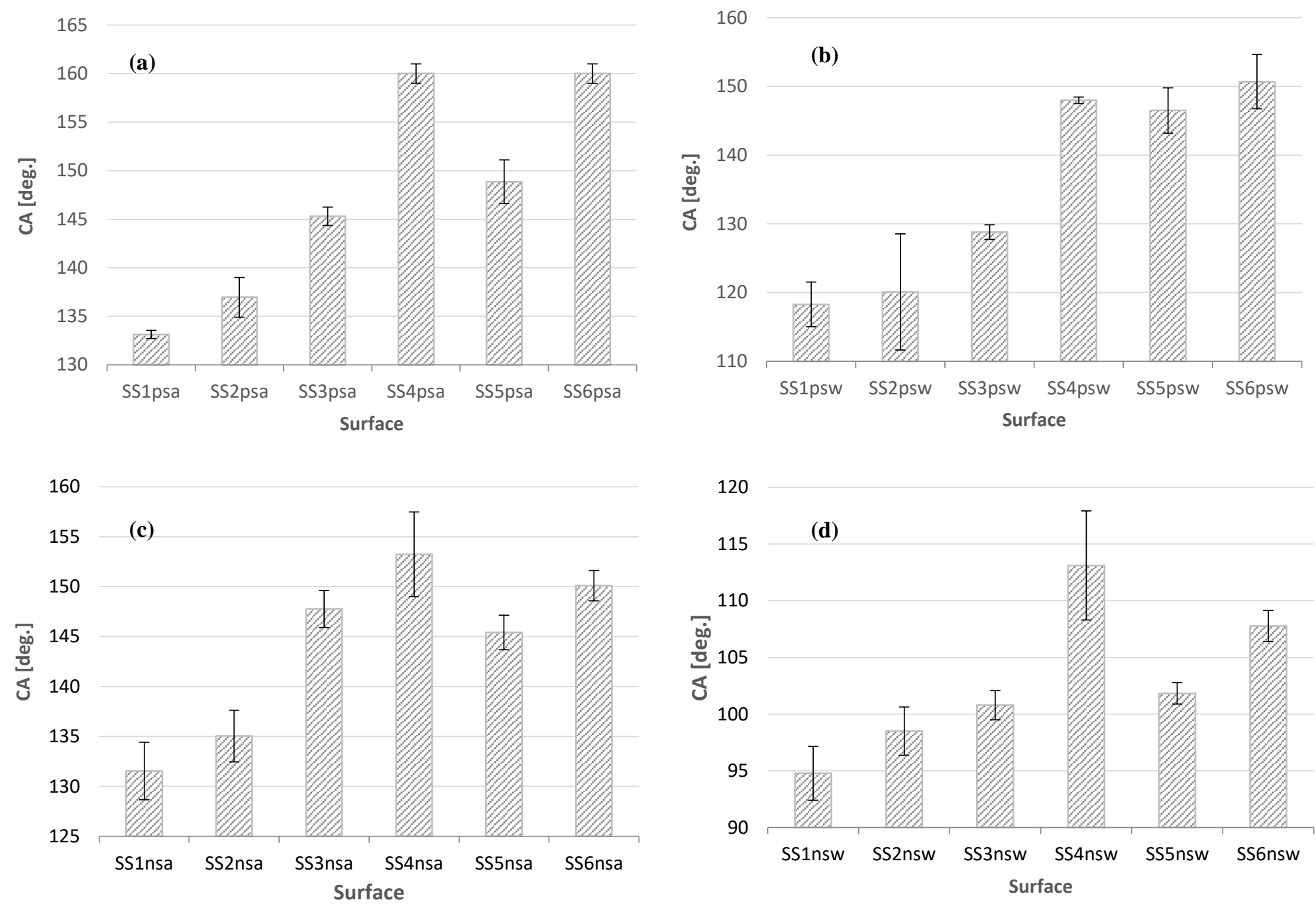

Fig. 7. Contact angle measurements of SS surfaces prepared using (a) ps texturing in air, (b) ps texturing in water, (c) ns texturing in air and (c) ns texturing in water. 
Tables 2 - 5 listed the atomic ratios of the surface chemical composition of laser treated surfaces. The chemical composition of untreated stainless steel samples was measured to be as follows: $64.86 \% \mathrm{Fe}, 17.28 \% \mathrm{Cr}, 9.38 \% \mathrm{Ni}, 1.41 \% \mathrm{Mo}, 0 \% \mathrm{O}, 3.96 \% \mathrm{~N}, 1.91 \% \mathrm{C}, 0.57 \% \mathrm{~F}$ and 0.61 $\% \mathrm{Si}$. The fluorine and silicon was coming from chemical treatment. It is clear that the oxygen and fluorine components were increased after the laser and chemical treatment. The oxygen percentage of the laser treated surfaces in the air was higher than that treated in the water. The oxygen and fluorine levels were increased with reducing the scanning speed (SS4). The SS6 witnessed highest oxygen and fluorine content for all the cases (SS6psa, SS6psw, SS6nsa and SS6nsw). SS1 recorded the lowest oxygen and fluorine percentages. Increasing the oxygen level was related to the reaction of ablated, melted and redeposited particles with oxygen molecules that existed in the air and water surrounding hot medium $[29,35,46]$. All surfaces were prepared at the same time and were treated after laser processing with $1 \%$ heptadecafluoro-1,1,2,2-tetrahydro-decyl-1-trimethoxysilane $\left(\mathrm{CF}_{3}\left(\mathrm{CF}_{2}\right)_{7}\left(\mathrm{CH}_{2}\right)_{2} \mathrm{Si}\left(\mathrm{OCH}_{3}\right)_{3}\right.$ methanol solution for $2 \mathrm{hrs}$ followed by washing in ethanol and drying in an oven at $80^{\circ} \mathrm{C}$ for 30 minutes in the same container and at the same time. Therefore, the amount of the absorbed fluorine percentage was mainly dependent on the oxygen percentage after laser processing which was mainly dependent on the laser processing parameters. As the oxide layer percentages of the laser treated samples in air were higher than the oxide layer perecntages of laser treated samples under water, the fluorine percentages of laser treated samples in air were higher than fluorine percentages of laser treated samples under water. Indeed, for same set of samples, such as samples treated using ps laser in air, it was noticed that with decreasing the scanning speed (SS1 to SS4), the oxygen percentage (1.49\% to $16.86 \%)$ and the fluorine percentage $(0.12 \%$ to $18.98 \%)$ were increased. The same behaviour was noticed with increasing the scanning pass to 10 passes (SS2 $(500 \mathrm{~mm} / \mathrm{s}, 1$ pass) to SS5 $(500 \mathrm{~mm} / \mathrm{s}, 10$ passes) and SS3 (50 $\mathrm{mm} / \mathrm{s}, 1$ pass) to SS6 (50 mm/s, 10 passes)) where O \% was increased from $2.51 \%$ (SS2) to 11.21 $\%$ (SS5) and from $12.25 \%$ (SS3) to $23.42 \%$ (SS6) with increasing the scanning time to 10 passes. $\mathrm{F} \%$ was also increased from $0.96 \%$ (SS2) to $9.45 \%$ (SS5) and $13.43 \%$ (SS3) to $21.81 \%$ (SS6) with increasing the scanning time to 10 passes. Several studies have reported that the surface oxidation of laser-induced structures is related to the oxygen molecules that exist in air or water which react with the surface during laser processing at high temperatures. During laser processing, the surface was melted which in turn led to the diffusion of oxygen through the molten material and final oxidising of the treated surface. Furthermore, when the surface particles were evaporated at high fluence, they reacted with the surrounding oxygen. Then the redepositing of these oxidised particles in addition to oxidised melted particle would occur [29, 35, 47]. However, the oxegen percentages of laser treated samples in water were lower than the oxygen percentages of surfaces treated in air. The amount of used water was low. Therefore, the amount of oxygen during laser 
processing in water was limited to the amount of oxygen of this small amount of water resulting in confining the interaction of the molten material with oxygen which in turn affected the final amount of surface oxygen contents. The prevention of redeposition of ablated particle as well as plasma shielding at high laser fluence, which prevents the surface interacting with the surrounding environment, might be another reason for low oxygen rate in water [29, 35]. It was proved that the amount of adsorbed substances on the surface was dependent on the surface $\mathrm{OH}$ group density of metal oxide. This fact indicates that the surface $\mathrm{OH}$ (hydroxyl) group density is a major factor governing the adsorption substances on the surface [29]. Therfore, it can be said that with increasing the scanning times/decreasing the scanning speed, the oxidising layer increased resulting in increasing the $\mathrm{OH}$ group density which affects the adsorption of flourine percentage to increase. 
Table 2

The atomic percentage of surfaces treated using ps laser in air.

\begin{tabular}{|l|c|c|c|c|c|c|c|c|c|c|c|}
\hline \multirow{2}{*}{ Surface } & \multicolumn{9}{|c|}{ EDX (\%) } \\
\cline { 2 - 13 } & $\mathbf{F e}$ & $\mathbf{C r}$ & $\mathbf{N i}$ & Mo & $\mathbf{O}$ & $\mathbf{N}$ & $\mathbf{C}$ & F & Si & O:SS & F:SS \\
\hline SS1psa & 64.02 & 17.18 & 9.1 & 1.21 & 1.49 & 4.2 & 2.3 & 0.12 & 0.39 & 0.016 & 0.001 \\
\hline SS2psa & 62.18 & 16.41 & 8.22 & 1.32 & 2.51 & 4.77 & 2.87 & 0.96 & 0.76 & 0.028 & 0.011 \\
\hline SS3psa & 44.84 & 10.54 & 6.43 & 1.29 & 12.25 & 2.72 & 7.38 & 13.43 & 1.12 & 0.194 & 0.213 \\
\hline SS4psa & 36.88 & 9.66 & 5.1 & 0.91 & 16.86 & 2.33 & 7.9 & 18.98 & 1.38 & 0.32 & 0.361 \\
\hline SS5psa & 48.67 & 12.67 & 6.92 & 1.27 & 11.21 & 2.17 & 6.47 & 9.45 & 1.16 & 0.161 & 0.136 \\
\hline SS6psa & 29.85 & 10.12 & 3.19 & 0.73 & 23.42 & 2.24 & 6.55 & 21.81 & 2.08 & 0.534 & 0.497 \\
\hline
\end{tabular}

Table 3

The atomic percentage of surfaces treated using ps laser in water.

\begin{tabular}{|c|c|c|c|c|c|c|c|c|c|c|c|}
\hline \multirow{2}{*}{ Surface } & \multicolumn{11}{|c|}{$\operatorname{EDX}(\%)$} \\
\hline & $\mathrm{Fe}$ & $\mathrm{Cr}$ & $\mathbf{N i}$ & Mo & $\mathbf{O}$ & $\mathbf{N}$ & $\mathbf{C}$ & $\mathbf{F}$ & Si & O:SS & F:SS \\
\hline SS1psw & 64.39 & 16.88 & 9.07 & 1.1 & 0.06 & 4.89 & 2.02 & 0.32 & 0.76 & 0.001 & 0.004 \\
\hline SS2psw & 62.57 & 17.07 & 8.76 & 1.53 & 0.33 & 5.57 & 2.6 & 0.77 & 0.81 & 0.003 & 0.009 \\
\hline SS3psw & 62.26 & 16.8 & 8.44 & 1.48 & 1.02 & 3 & 5.23 & 1.08 & 0.7 & 0.011 & 0.012 \\
\hline SS4psw & 64.34 & 17.49 & 8.94 & 1.21 & 1.24 & 2.52 & 1.81 & 2.09 & 0.37 & 0.013 & 0.023 \\
\hline SS5psw & 62.17 & 16.72 & 8.87 & 1.48 & 0.71 & 5.11 & 3.64 & 0.52 & 0.74 & 0.008 & 0.006 \\
\hline SS6psw & 61.82 & 16.8 & 8.65 & 1.49 & 1.71 & 3.56 & 2.78 & 2.37 & 0.79 & 0.02 & 0.03 \\
\hline
\end{tabular}


Table 4

The atomic percentage of surfaces treated using ns laser in air.

\begin{tabular}{|l|c|c|c|c|c|c|c|c|c|c|c|}
\hline \multirow{2}{*}{ Surface } & \multicolumn{10}{|c|}{ EDX (\%) } \\
\cline { 2 - 13 } & $\mathbf{F e}$ & $\mathbf{C r}$ & $\mathbf{N i}$ & $\mathbf{M o}$ & $\mathbf{O}$ & $\mathbf{N}$ & $\mathbf{C}$ & $\mathbf{F}$ & $\mathbf{S i}$ & $\mathbf{0 : S S}$ & F:SS \\
\hline SS1nsa & 51.06 & 13.42 & 7.25 & 1.51 & 9.37 & 3.74 & 6.88 & 6.24 & 0.88 & 0.127936 & 0.085199 \\
\hline SS2nsa & 43.35 & 10.53 & 6.29 & 1.16 & 13.36 & 3.6 & 7.56 & 12.98 & 1.17 & 0.217838 & 0.211642 \\
\hline SS3nsa & 37.3 & 9.78 & 5.21 & 0.81 & 17.22 & 2.45 & 7.73 & 18.23 & 1.27 & 0.324294 & 0.343315 \\
\hline SS4nsa & 29.27 & 9.82 & 3.12 & 0.64 & 23.71 & 3.11 & 6.92 & 21.58 & 1.83 & 0.553326 & 0.503617 \\
\hline SS5nsa & 40.08 & 9.35 & 5.76 & 0.73 & 16.81 & 1.68 & 9.54 & 15.52 & 0.54 & 0.300608 & 0.277539 \\
\hline SS6nsa & 24.98 & 6.39 & 3.53 & 0.5 & 25.76 & 3.06 & 9.43 & 25.52 & 0.83 & 0.727684 & 0.720904 \\
\hline
\end{tabular}

Table 5

The atomic percentage of surfaces treated using ns laser in water.

\begin{tabular}{|l|c|c|c|c|c|c|c|c|c|c|c|}
\hline \multirow{2}{*}{ Surface } & \multicolumn{9}{|c|}{ EDX (\%) } \\
\cline { 2 - 13 } & $\mathbf{F e}$ & $\mathbf{C r}$ & $\mathbf{N i}$ & $\mathbf{M o}$ & $\mathbf{O}$ & $\mathbf{N}$ & $\mathbf{C}$ & $\mathbf{F}$ & $\mathbf{S i}$ & $\mathbf{0 : S S}$ & F:SS \\
\hline SS1nsw & 63 & 16.42 & 9.25 & 1.52 & 1.85 & 4.68 & 1.99 & 0.17 & 1.11 & 0.020512 & 0.001885 \\
\hline SS2nsw & 62.77 & 16.55 & 8.77 & 1.5 & 2.43 & 4.28 & 2.35 & 0.3 & 1.05 & 0.027124 & 0.003349 \\
\hline SS3nsw & 61.78 & 16.63 & 8.71 & 1.39 & 3.1 & 5.46 & 1.49 & 0.61 & 0.84 & 0.031355 & 0.004686 \\
\hline SS4nsw & 62.56 & 16.64 & 8.5 & 1.38 & 3.42 & 3.16 & 2.51 & 0.7 & 1.12 & 0.038392 & 0.007858 \\
\hline SS5nsw & 62.73 & 16.6 & 8.81 & 1.48 & 2.81 & 4.16 & 2.11 & 0.42 & 0.87 & 0.031355 & 0.004686 \\
\hline SS6nsw & 59.17 & 15.85 & 8.47 & 1.39 & 6.06 & 4.78 & 2.3 & 1.33 & 0.64 & 0.071395 & 0.015669 \\
\hline
\end{tabular}


The surfaces kept in air did not lose their wettability characteristics even after two years of preparation; whereas the surfaces kept in water behaved differently depending on surface characteristics and water conditions. The ageing experiment of the laser-treated samples was conducted, for 8 months, under three different conditions of water (hot, normal and iced) (Fig.s 8 - 11). Overall, the surfaces kept in hot water lost durability quicker than did the samples kept in normal and iced waters. Conversely, the samples left in iced water, sustained dry for long time. Indeed, the durability of the surfaces treated using ns laser was higher than the durability of the surfaces treated using ps laser. Fig. 8 shows the ageing results of surfaces treated using ps laser in air. It is clear that the control surfaces lost their durability and became wet after one day. There was not a remarkable difference in the durability results between the surfaces kept in hot and normal water as in both cases, the treated surfaces lost their durability within a week from water immersion. However, the surfaces kept in iced water sustained dry under water for a longer period of time (SS1 (5 weeks), SS2 (5 weeks) and SS3 (10 weeks)). SS3, on the other hand, sustained dry under water for 5 months. The experiment was performed for 8 months; some surfaces stayed dry throughout the experiment time (SS4 and SS6). These surfaces were plotted with grid bars.

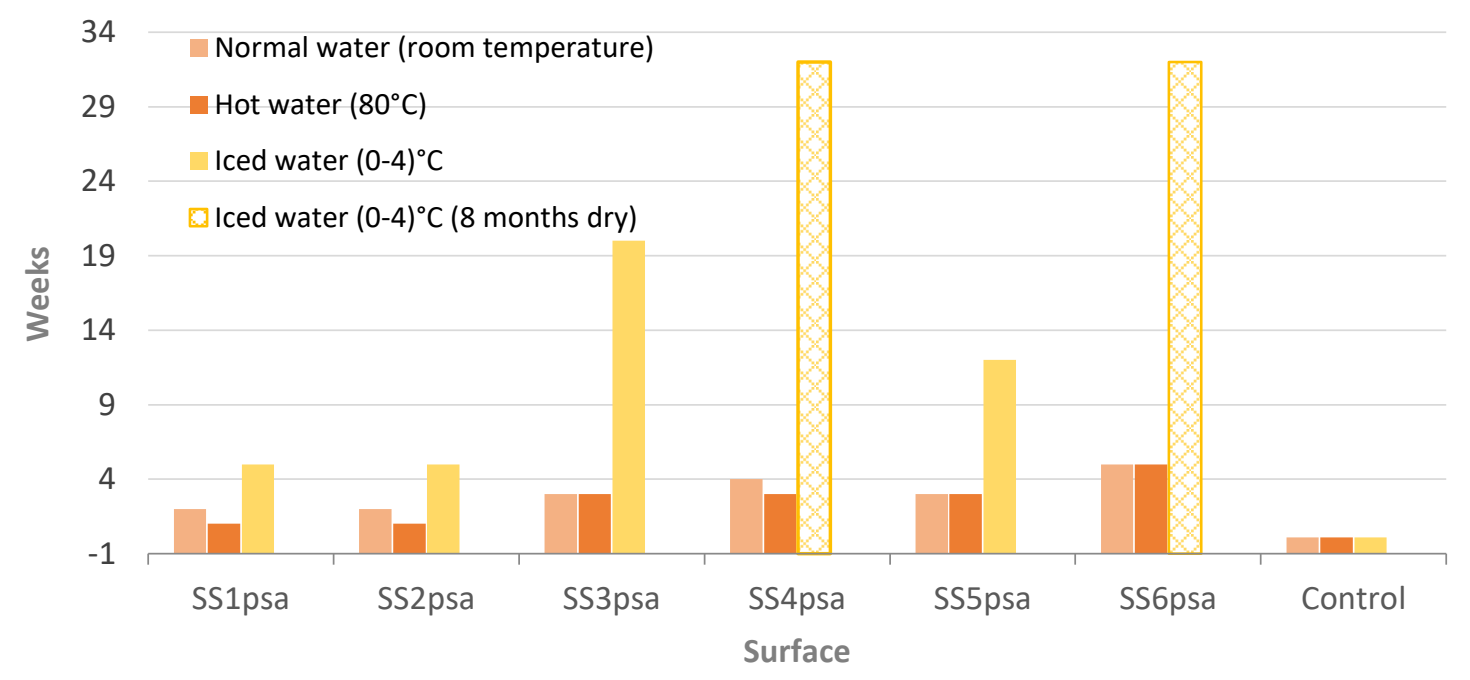

Fig. 8. Durability of hydrophobic surfaces in different water conditions for the surfaces generated using ps laser texturing SS in air.

Unlike the surfaces treated in air, the durability of surfaces prepared in water was lower than that of the surfaces prepared in air (Fig. 9). Indeed, there is no noticeable difference between the hot and normal water results. Almost all surfaces sustained dry under water for 2-3 weeks. However, SS6 recorded the maximum dry period of 12 weeks, and SS1 sustain dry under water for one week. 


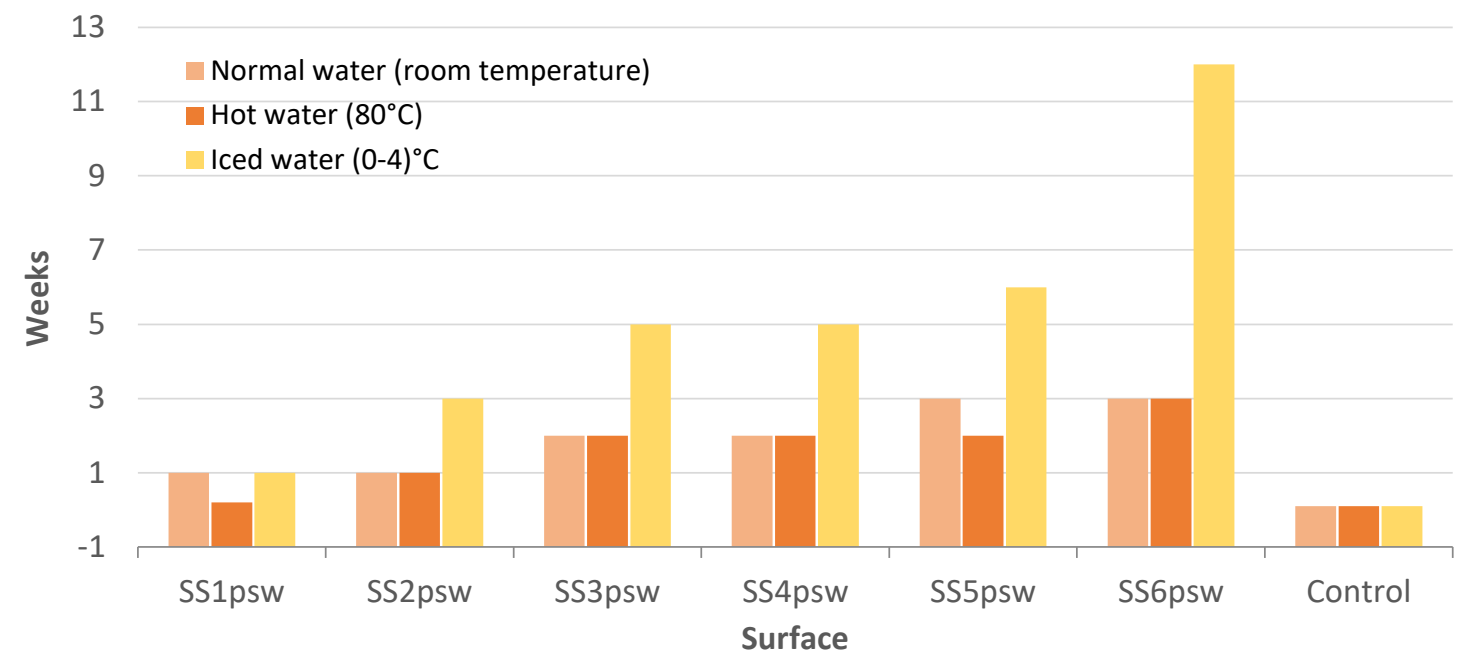

Fig. 9. Durability of hydrophobic surfaces in different water conditions for the surfaces generated using ps laser texturing SS in water.

The durability of surfaces treated using ns laser in air and water is shown in Fig. 10 and Fig. 11, respectively. The durability of surfaces treated in air was much higher than that treated in water. Regarding the surfaces prepared in air then immersed in hot water (SS1 and SS2) were associated with the least durability, and they sustained dry under water for 1 week, while in normal water (room temperature) they sustained dry for 3 weeks. In the iced water, the same surfaces sustained dry under water for 8 months. SS4 and SS6 behaved similarly in hot water, and both sustained dry under the hot water for 8 weeks. In normal water, SS6 was associated with the higher value and stayed dry for 14 weeks, while SS4 stayed dry for 12 weeks. Moreover, in ice, SS3, SS4, SS5 and SS6 stayed dry during the experiment time. For the surfaces treated in water (Fig. 11), surface durability ranged between 1 week for hot to 2 weeks for normal water as recorded for SS1. Durability of 2 weeks in both hot and normal water was recorded for SS2, SS3 and SS5. SS4 sustained dry under water for slightly longer period of time ( 3 weeks) in both hot and normal water compared with SS2, SS3 and SS5. SS6 sustained dry for 3 weeks under hot water and 4 weeks in normal water. In iced water, both SS4 and SS6 behaved similarly and sustained dry for 12 weeks. SS1 showed the least durability of sustaining dry under water of 3 weeks. 


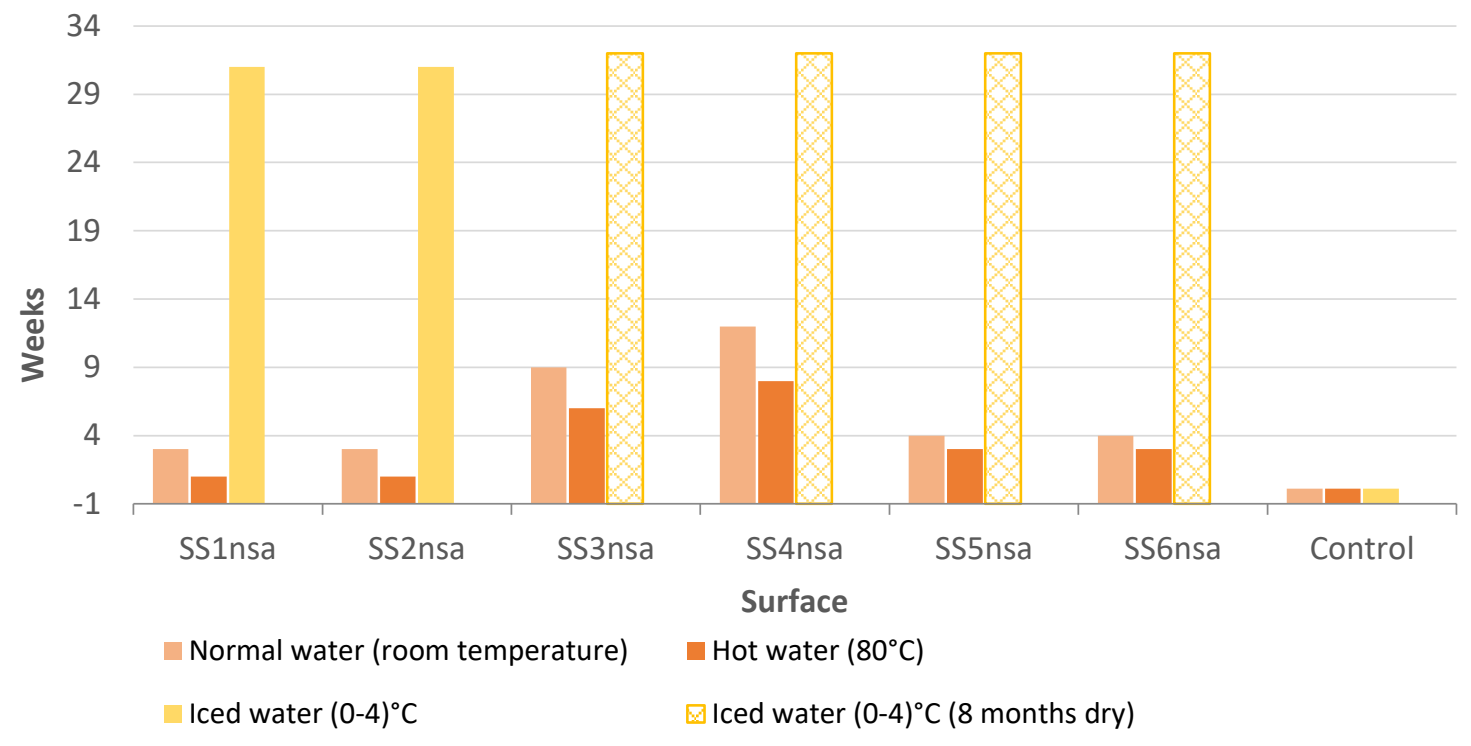

Fig. 10. Durability of hydrophobic surfaces under different water conditions for the surfaces generated using ns laser-texturing of SS in air.

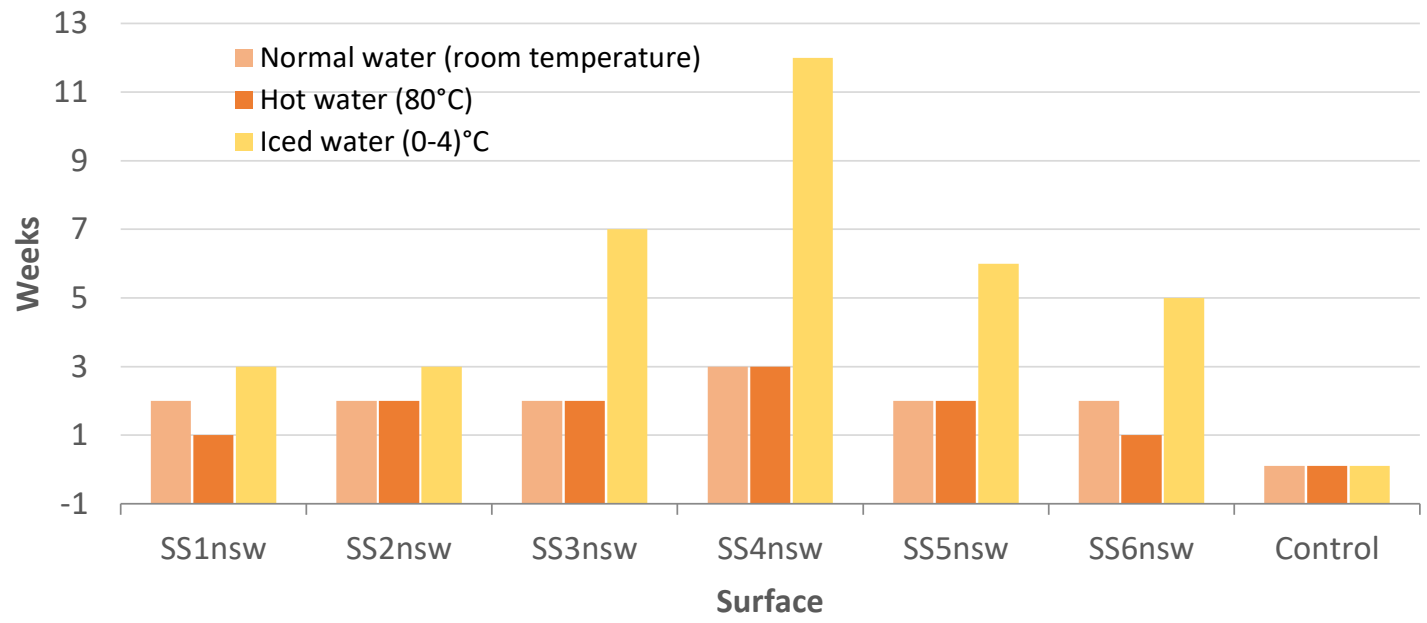

Fig. 11. Durability of hydrophobic surfaces in different water conditions for the surfaces generated using ns laser texturing SS in water

It is clear that the durability of sustaining dry surface under water was affected by surface roughness and fluorine percentage. The surfaces treated in air recorded highest durability than that treated in air. This could be related to the highest roughness values and fluorine percentage of surface treated in air compared with that treated in water. As it can be noticed that SS1psw and SS1nsw had lower roughness value and lower fluorine percentage, they recorded the lowest durability under water; whereas, SS4 and SS6 having the highest durability as these substrates were of higher roughness and higher fluorine percentage compared with other surfaces (SS1, SS2, SS3 and SS5). With increasing the roughness, the fluorine percentage was increased affecting the 
durability. This might be related to form an isolating layer which increased the air pockets between the surface and the water.

SEM images of samples after 8 months of the durability test are shown in Fig. 12. The figure shows the SEM images of microstructure for samples treated using ps laser in air and using 10 $\mathrm{mm} / \mathrm{s}$ (SS4). As the samples left in hot and normal water were lost their durability while the sample left in iced water sustained dry for 8 months, the test was focused on analysing the microstructure of the samples kept in hot and iced water. It is clear that there was no difference in the microstructure of samples kept in iced water (Fig. 12b) compared with the microstructure of the sample after laser treatment (Fig. 12a). Both images showed that the microstructure included 3D micro/nanostructures. The nanoparticles covered the microstructure. However, the microstructure of the sample kept in hot water (Fig. 12c) was different from that kept in iced water. Some submicron / nanostructures were disappeared, and the surfaces became smoother than that kept in iced water. EDX analysis (Fig. 12d,e and Table 6), on the other hand, showed that there was a big difference between the three tested samples. The oxidation of samples kept in iced and hot water increased compared to the sample after laser treatment. The samples left in hot water showed the highest O \% (20.1\%) compared to that left in iced water (17.97\%) which showed slightly higher $\mathrm{O} \%(17.97 \%)$ than $\mathrm{O} \%$ of the sample after laser treatment $(16.89 \%)$. The results also showed that the fluorine layer of the sample kept in hot water was disappeared as the F \% and $\mathrm{Si} \%=0 \%$. However, the sample kept in iced water saved its fluorine layer after 8 months but the ratio (7.8\% $\mathrm{F}$ and $1.14 \% \mathrm{Si}$ ) was lower than the ration of the fluorinated layer after laser treatment (18.98\% $\mathrm{F}$ and $1.38 \% \mathrm{Si}$ ). The disappearance of fluorinated layer interpreted the reason behind losing the durability of sustaining dry surface under hot water. The water affected the fluorinated layer to decrease with time and after losing the fluorinated layer, the sample lost its durability of sustaining dry. Due to the presence of fluorinated layer over the sample kept in iced water after 8 months of conducting the test, the sample sustained dry under iced water.

Table 6

The atomic percentage ratio of laser treated samples (EDX analysis)

\begin{tabular}{|l|c|c|c|c|c|c|c|c|c|c|c|}
\hline Surface & $\mathbf{F e}$ & $\mathbf{C r}$ & $\mathbf{N i}$ & $\mathbf{M o}$ & $\mathbf{O}$ & $\mathbf{N}$ & $\mathbf{C}$ & $\mathbf{F}$ & Si & O:SS & F:SS \\
\hline After laser & 36.88 & 9.66 & 5.1 & 0.91 & 16.86 & 2.33 & 7.9 & 18.98 & 1.38 & 0.32 & 0.361 \\
\hline After durability test (iced) & 44.97 & 12.49 & 5.8 & 0.97 & 17.97 & 4.56 & 4.26 & 7.8 & 1.14 & 0.28 & 0.12 \\
\hline After durability test (hot) & 53.26 & 13.51 & 8.84 & 1 & 20.1 & 2.72 & 0.8 & 0 & 0 & 0.26 & 0 \\
\hline
\end{tabular}



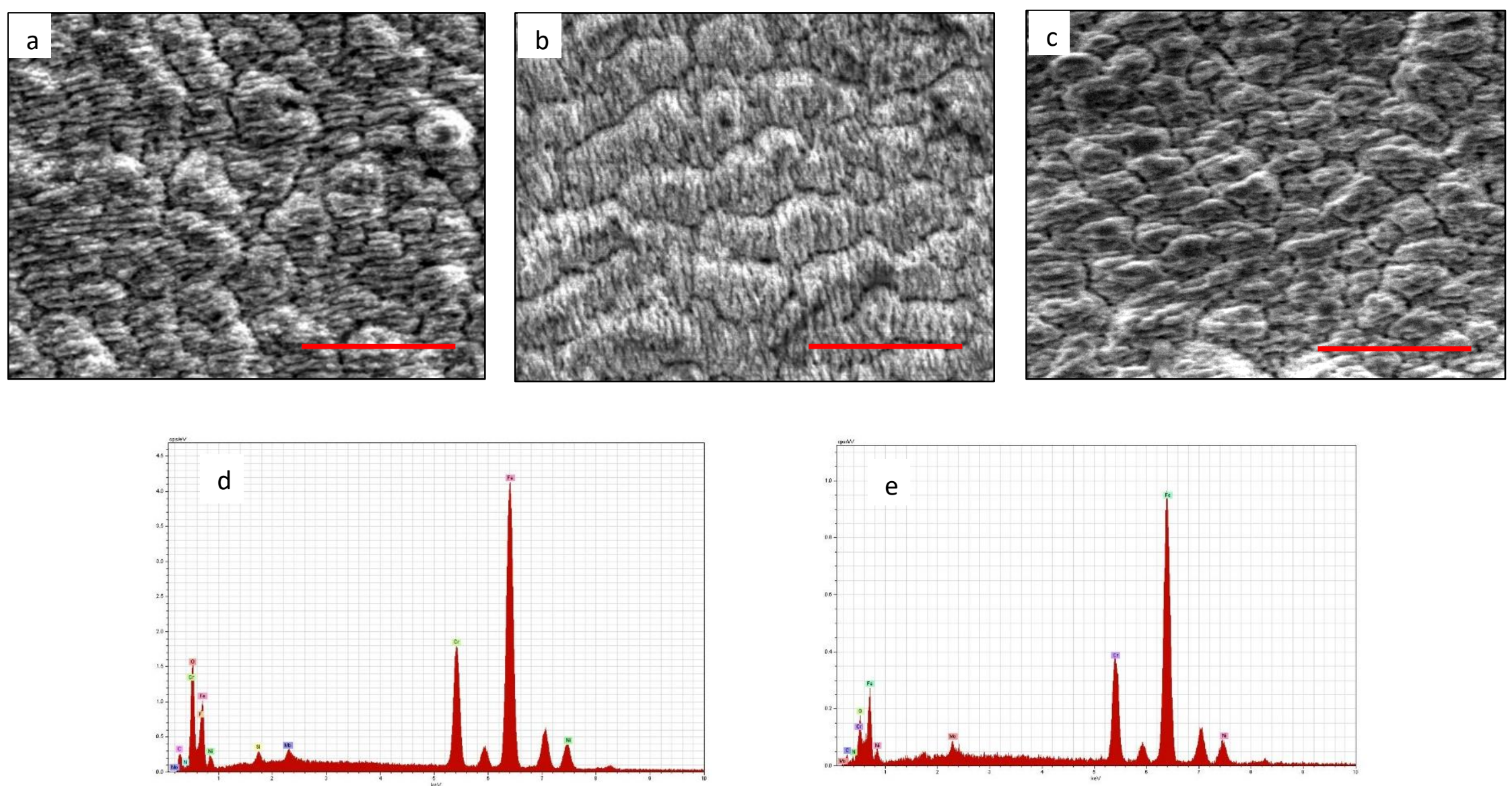

Fig. 12. The effect of water on microstructure of stainless steel surfaces treated by ps laser in air using $10 \mathrm{~mm} / \mathrm{s} \mathrm{scanning} \mathrm{speed.} \mathrm{(a)} \mathrm{microstructure} \mathrm{of} \mathrm{sample} \mathrm{after} \mathrm{laser}$ treatment, (b) microstructure of sample saved in iced water, (c) microstructure of sample saved in hot water, (d) EDX of sample saved in iced water and (f) EDX of sample saved in hot water. Scale bar is $20 \mu \mathrm{m}$. 


\subsection{Hybrid surfaces production}

The ps and ns were used to prepare the hybrid surface (surface of hydrophobic/hydrophilic areas). Fig. 13 shows the samples that were prepared using ps and ns laser-textured 316L stainless steel (SS) samples. Fig. 13a and Fig. 13b show two surfaces of $\left(3 \times 3 \mathrm{~cm}^{2}\right)$, and each surface contains two areas with an interior area of $\left(1 \times 1 \mathrm{~cm}^{2}\right)$ that were prepared using ps laser texturing of SS substrate. The dark areas of both surfaces were prepared using laser processing parameters of 10 $\mu \mathrm{m}$ hatch distance, $10 \mathrm{~mm} / \mathrm{s}$ scanning speed, 1 scanning pass and $0.177 \mathrm{~J} / \mathrm{cm}^{2}$ laser fluence. The shiny interior area of the first surface (Fig. 13a) was prepared using ps laser parameters of $10 \mu \mathrm{m}$ hatch distance, $1000 \mathrm{~mm} / \mathrm{s}$ scanning speed, 1 scanning pass and $0.177 \mathrm{~J} / \mathrm{cm}^{2}$ laser fluence; whereas, the shiny exterior area of the surface in Fig. 13b was prepared using ps laser parameters of $50 \mu \mathrm{m}$ hatch distance, $1000 \mathrm{~mm} / \mathrm{s}$ scanning speed, 1 scanning pass and $0.177 \mathrm{~J} / \mathrm{cm}^{2}$ laser fluence. Fig. $13 \mathrm{c}$ shows a surface of $\left(3 \times 3 \mathrm{~cm}^{2}\right)$ which had two areas with an interior area of $\left(1 \times 1 \mathrm{~cm}^{2}\right)$. The exterior area was prepared using ps laser processing parameters of $10 \mu \mathrm{m}$ hatch distance, 1000 $\mathrm{mm} / \mathrm{s}$ scanning speed, 1 scanning pass and $0.177 \mathrm{~J} / \mathrm{cm}^{2}$ laser fluence, whilst the $\left(1 \times 1 \mathrm{~cm}^{2}\right)$ interior area was prepared using ns laser processing parameters of $(50 \mu \mathrm{m}$ hatch distance, $500 \mathrm{~mm} / \mathrm{s}$ scanning speed, 100 scanning passes and $9.2 \mathrm{~J} / \mathrm{cm}^{2}$ laser fluence). The interior area was prepared by covering the area with the glass substrate.

Fig. 13d shows surfaces prepared using ns the laser-surface texturing. There are four numbers labeled the rwos; each number represents different laser processing parameters that used to process the labled row. The processing parameters that used to prepare the surfaces of each row is listed in Table 7. 

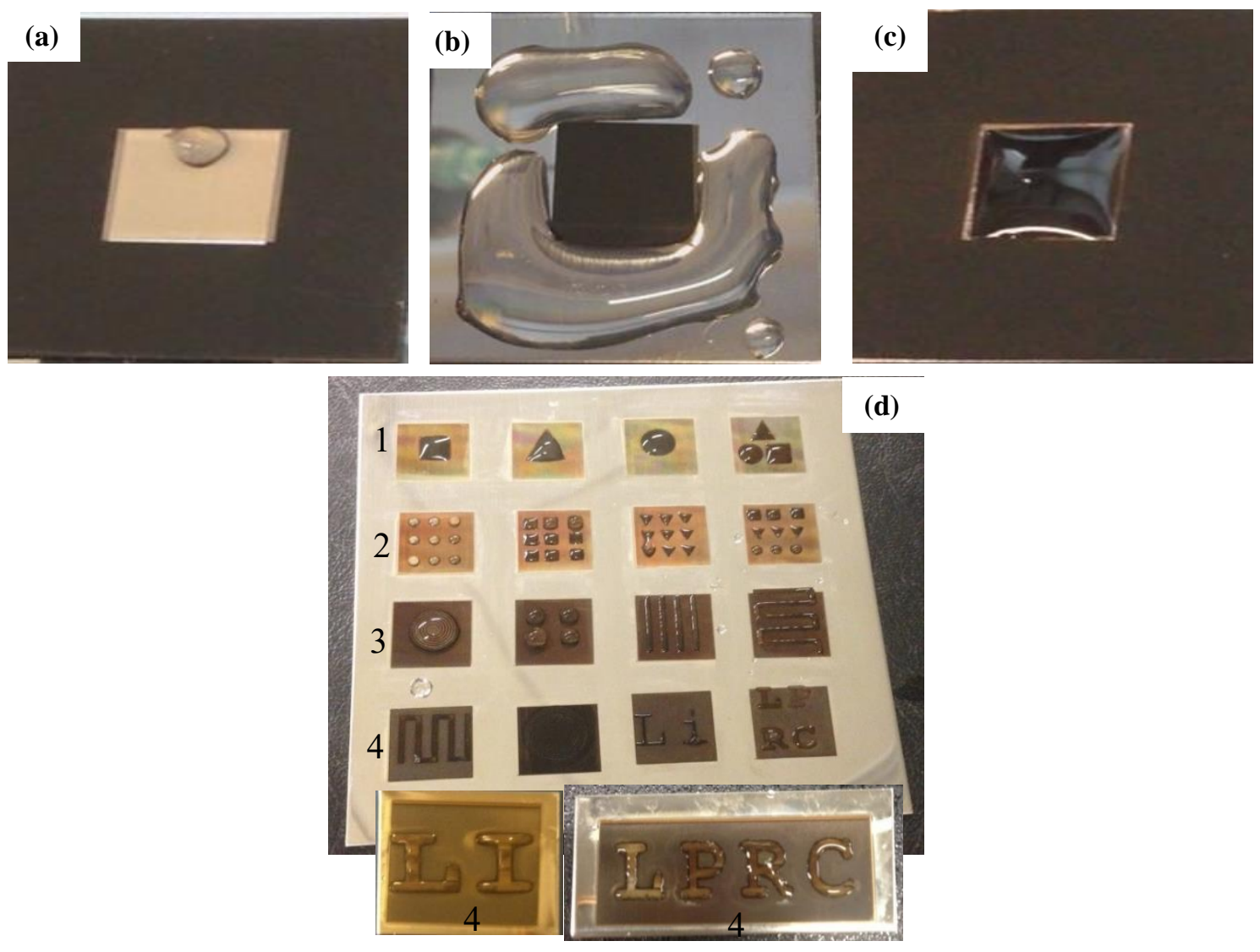

Fig. 13. (a) ps laser textured SS samples with superhydrophobic/hydrophilic areas, (b) ps laser textured SS samples with hydrophilic/superhydrophobic areas (c) superhydrophobic/superhydrophilic areas produced using ps and ns laser surface texturing and (d) superhydrophobic/superhydrophilic and hydrophobic/superhydrophilic areas generated using ns laser textured SS substrate.

\section{Table 7}

Processing parameters used to prepare surfaces shown in Fig. 13d.

\begin{tabular}{|c|c|c|}
\hline Row & Dark area (low wettability) & Light area (high wettability) \\
\hline 1 & $\begin{array}{l}10 \mu \mathrm{m} \text { hatch distance, } 500 \mathrm{~mm} / \mathrm{s} \\
\text { scanning speed, } 1 \text { scanning pass and } 9.2 \\
\mathrm{~J} / \mathrm{cm}^{2} \text { laser fluence }\end{array}$ & $\begin{array}{l}50 \mu \mathrm{m} \text { hatch distance, } 500 \mathrm{~mm} / \mathrm{s} \text { scanning } \\
\text { speed, } 100 \text { scanning pass and } 9.2 \mathrm{~J} / \mathrm{cm}^{2} \text { laser } \\
\text { fluence }\end{array}$ \\
\hline 2 & $\begin{array}{l}10 \mu \mathrm{m} \text { hatch distance, } 500 \mathrm{~mm} / \mathrm{s} \\
\text { scanning speed, } 10 \text { scanning pass and } 9.2 \\
\mathrm{~J} / \mathrm{cm}^{2} \text { laser fluence }\end{array}$ & $\begin{array}{l}10 \mu \mathrm{m} \text { hatch distance, } 10 \mathrm{~mm} / \mathrm{s} \text { scanning } \\
\text { speed, } 1 \text { scanning pass and } 9.2 \mathrm{~J} / \mathrm{cm}^{2} \text { laser } \\
\text { fluence }\end{array}$ \\
\hline 3 & $\begin{array}{l}50 \mu \mathrm{m} \text { hatch distance, } 50 \mathrm{~mm} / \mathrm{s} \text { scanning } \\
\text { speed, } 10 \text { scanning pass and } 9.2 \mathrm{~J} / \mathrm{cm}^{2} \\
\text { laser fluence }\end{array}$ & $\begin{array}{l}10 \mu \mathrm{m} \text { hatch distance, } 10 \mathrm{~mm} / \mathrm{s} \text { scanning } \\
\text { speed, } 1 \text { scanning pass and } 9.2 \mathrm{~J} / \mathrm{cm}^{2} \text { laser } \\
\text { fluence }\end{array}$ \\
\hline 4 & $\begin{array}{l}50 \mu \mathrm{m} \text { hatch distance, } 10 \mathrm{~mm} / \mathrm{s} \text { scanning } \\
\text { speed, } 1 \text { scanning pass and } 9.2 \mathrm{~J} / \mathrm{cm}^{2} \text { laser } \\
\text { fluence }\end{array}$ & $\begin{array}{l}10 \mu \mathrm{m} \text { hatch distance, } 10 \mathrm{~mm} / \mathrm{s} \text { scanning } \\
\text { speed, } 1 \text { scanning pass and } 9.2 \mathrm{~J} / \mathrm{cm}^{2} \text { laser } \\
\text { fluence }\end{array}$ \\
\hline
\end{tabular}


Fig. 14 shows the SEM images and the contact angle measurements of the surface shown in Fig.s $13 \mathrm{a}$ and $\mathrm{b}$. It can be seen that the dark areas consisted multi-scale (micro-features covered by submicron features), and the light areas consisted of rippled features. The dark areas were surface of $\mathrm{CA}=160^{\circ}$. However, the CA of first and second light areas was, respectively, $72^{\circ}$ and $52^{\circ}$. These surfaces can be characterised as a hybrid surface of superhydrophobic/hydrophilic areas as the average $\mathrm{CA}$ of the dark areas was $>150^{\circ}$ (superhydrophobic) and of the light areas was $<90^{\circ}$ (hydrophilic). 


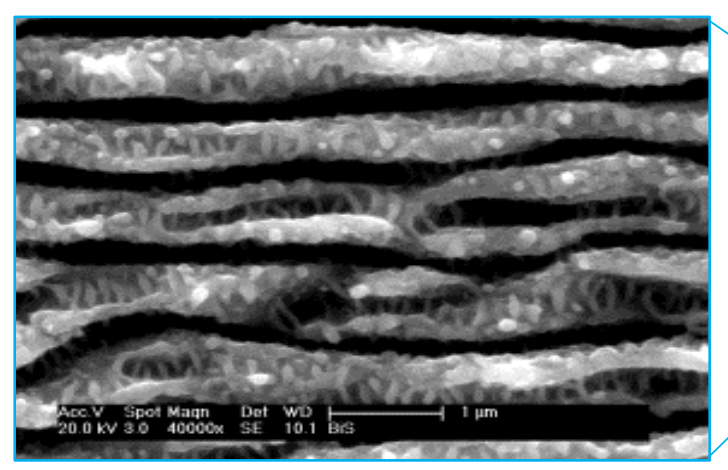

$71.65^{\circ} \pm 2.165^{\circ}$

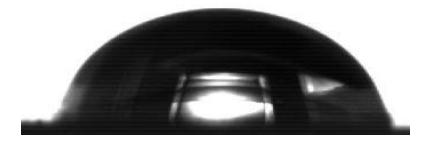

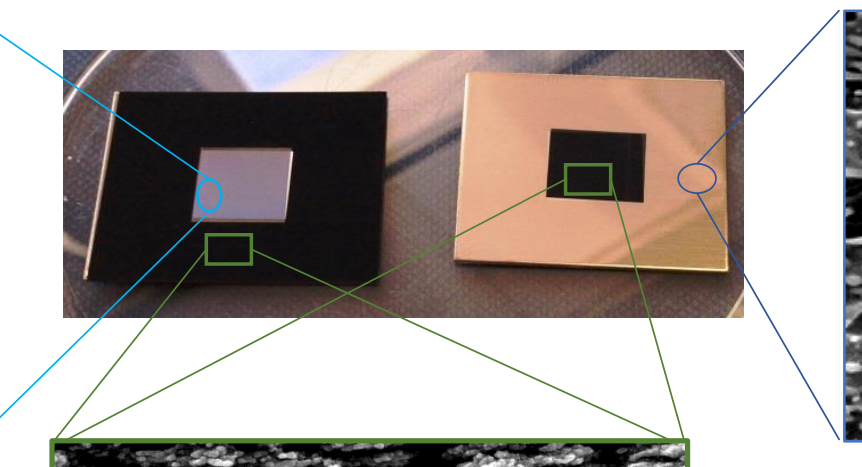

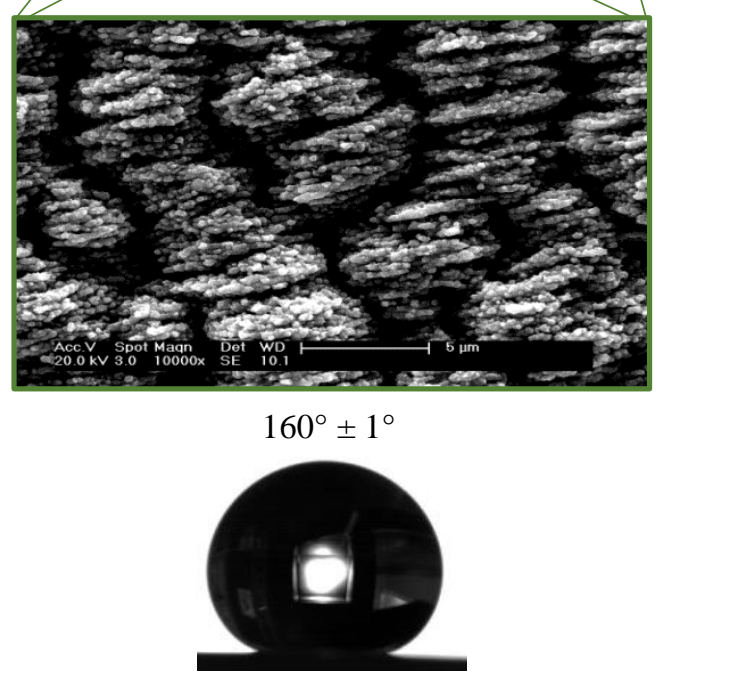

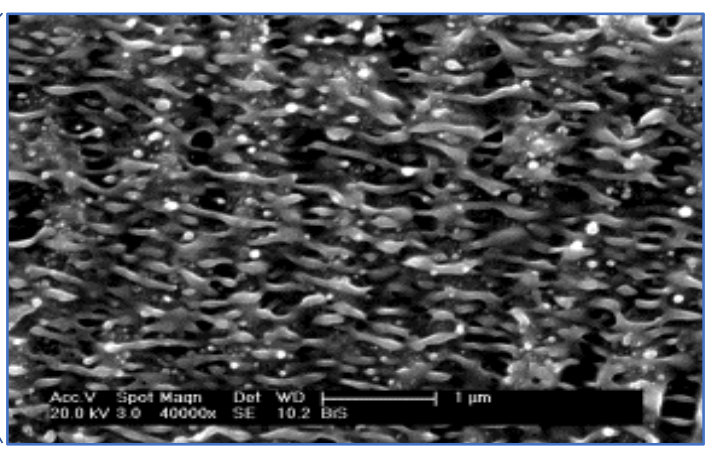

$52.32^{\circ} \pm 0.29^{\circ}$

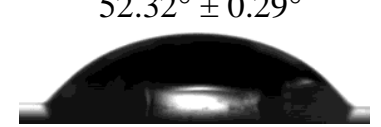

Fig. 14. SEM and CA measurements of superhydrophobic/hydrophilic surfaces prepared using ps laser surface texturing of SS substrate. 
It is noticeable that the CA of the exterior area surface presented in Fig. $13 \mathrm{c}$ was $160^{\circ}$, while the $\mathrm{CA}$ of the interior area was $0^{\circ}$ (Fig. 15). Due to these values of CA, this surface can be characterised as a hybrid surface of superhydrophobic/superhydrophilic areas. Preparing and texturing the superhydrophilic areas with the assisting of glass substrate resulted in a durability of the surface that lasted for more than 6 months. The SEM shows that the superhydrophobic area was of multi-scale structures with conical like structures which covered with sub-micron particles. The superhydrophilic areas showed microgrooves covered by sub-micron particles.

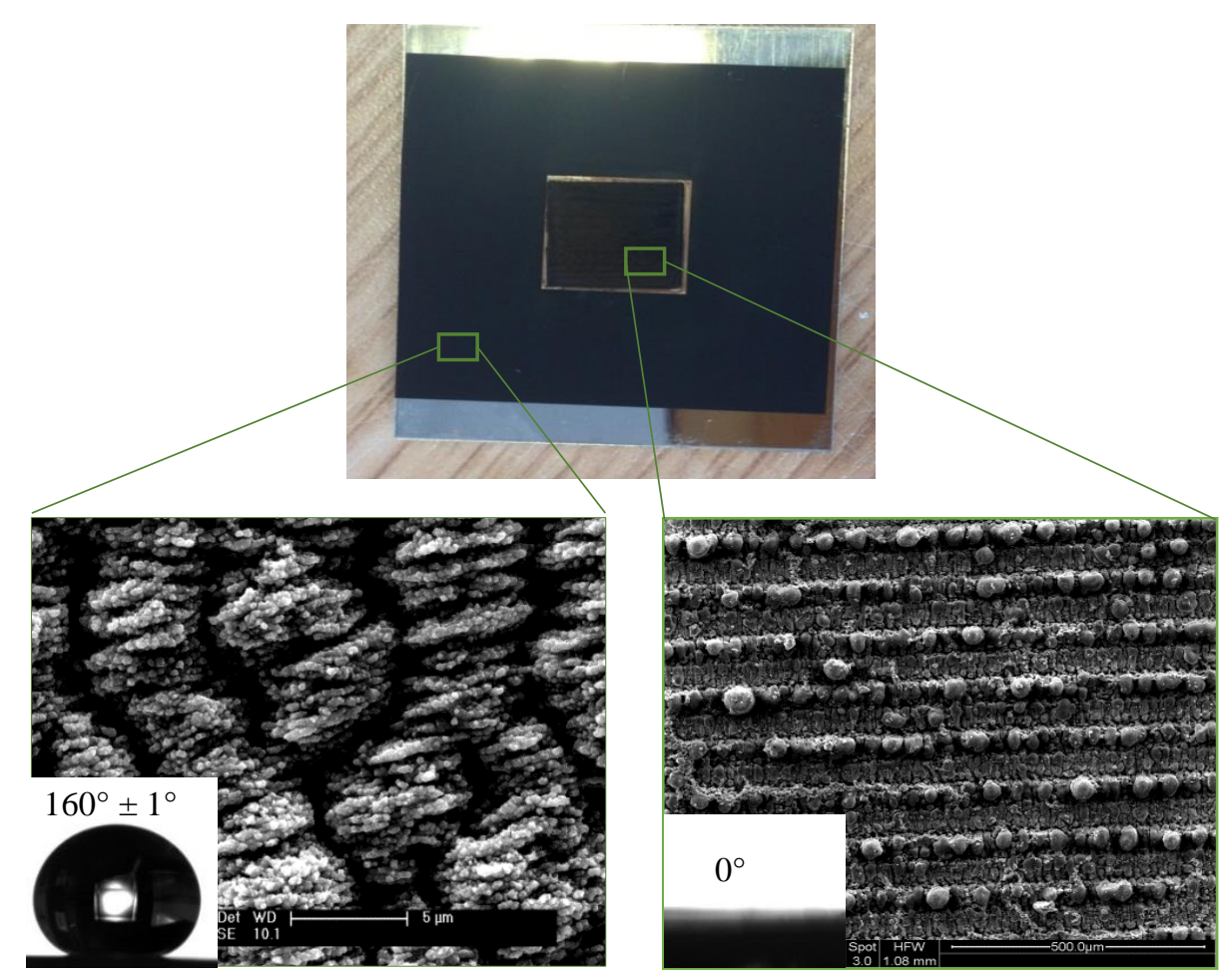

Fig. 15. SEM and CA measurements of superhydrophobic/superhydrophilic surface presented in Fig. 13c and prepared using ps (superhydrophobic area) and ns (superhydrophilic areas) laser surface texturing of SS surface.

Fig. 16 shows the SEM and CA measurements of the surfaces shown in Fig. 13d. The surfaces presented different patterns. These surfaces were prepared using the ns laser-surface texturing. Each row of these surfaces was prepared using different processing parameters resulting in different wettability characteristics. It can be seen from Fig. 16 that the CAs of surfaces in the first row (Fig. $16(1)$ ) were $135^{\circ}$ for the exterior areas and $0^{\circ}$ for the interior areas. Therefore, these surfaces can be characterised as hybrid surfaces of hydrophobic/superhydrophilic wettability. Similarly, surfaces in the second row (Fig. 16 (2)) can be characterised as a hybrid 
surface of hydrophobic/superhydrophilic properties as the average CAs of the big exterior box was $148^{\circ}$ while the average CA of the interior area was $0^{\circ}$. Surfaces in third and fourth rows presented in Fig. 13d can be characterised as a hybrid surface of superhydrophobic/superhydrophilic wettability. As the avearge CA of outer areas were higher than $150^{\circ}\left(165^{\circ}\right.$ [row 3] and $161^{\circ}$ [row 4] (see Fig. 16 (3) and (4)), therefore, they characterised as superhydrophobic. The interior patterned areas showed a CA of $0^{\circ}$ and can be charectrised as superhydrophilic areas; (see Fig. 16 (3) and (4)). The superhydrophilic areas were also prepared with the assisting of glass covering the stainless steel samples to assure high durability of the superhydrophilic areas following the authors' previous work [39].

The superhydrophobic and superhydrophilic areas generated using ps and ns laser surface texturing of SS did not lose its durability even after one year of preperation.

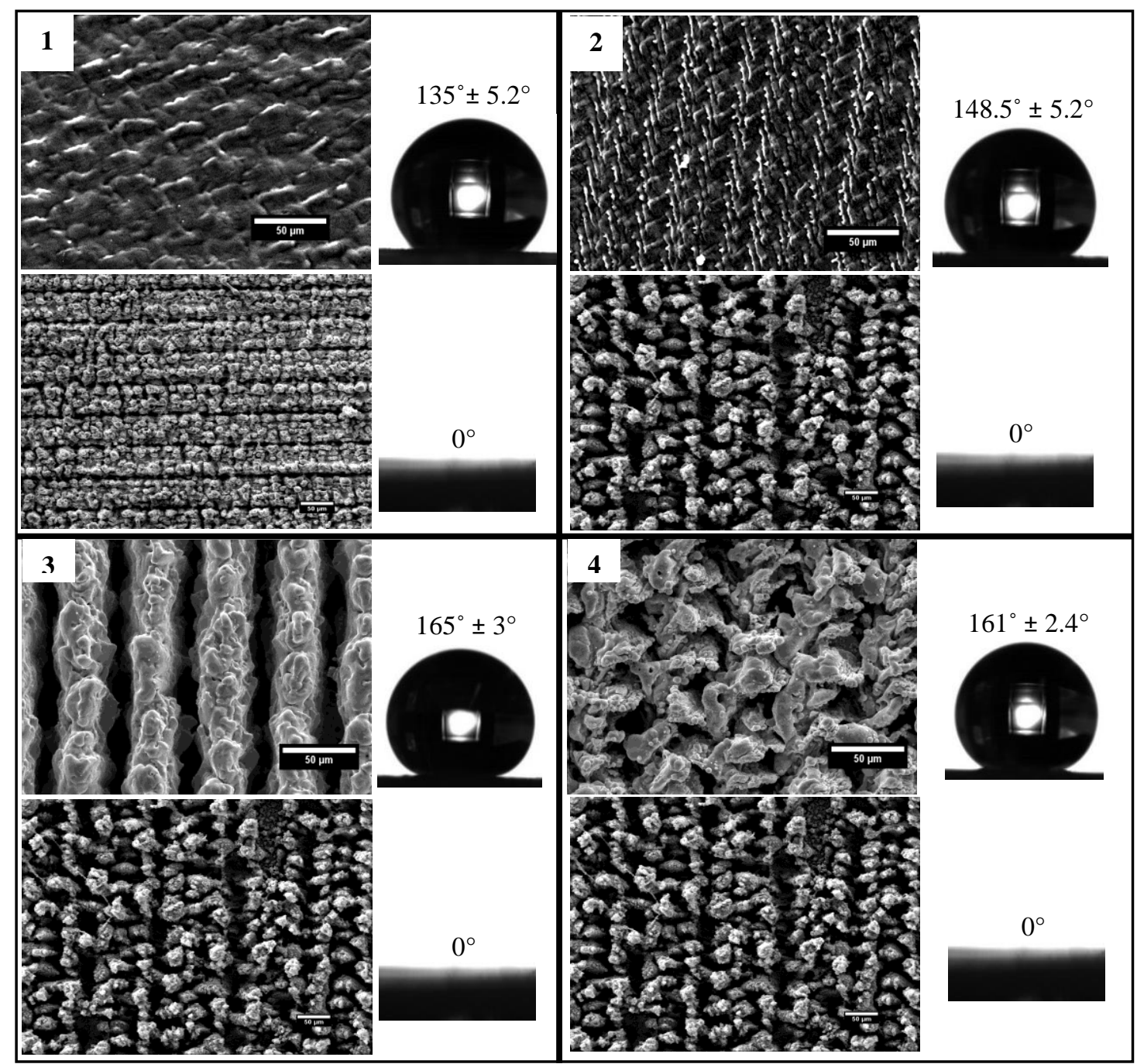

Fig. 16. SEM and CA measurements of Fig. 13d surfaces prepared using ns laser surface texturing of the hydrophobic/superhydrophilic surface $(1,2)$ and superhydrophobic/superhydrophilic surfaces $(3,4)$. 


\section{Conclusions}

In the current work, the durability of sustaining dry surfaces that produced using ps and ns laser surface texturing of SS under different conditions of water (hot, normal and iced water) was tested and analysed. The results showed that the surface of higher CA, higher surface roughness and higher fluorine composition sustained dry under water for a longer period compared with other surfaces, particularly in the cold icy water for at least 8 months. Durable surface in icy water conditions could be used in a range of applications like anti frost, airplanes and cables manufacturing. Hybrid surfaces were prepared using simple, repeatable and durable lasersurface texturing method. These surfaces can open a new opportunity of applications such as cell migration, printing and fluid flow controlling which are of great utility in different medical and industrial fields.

\section{Acknowledgements}

The authors acknowledge Iraqi Ministry of Higher Education and Scientific Research (MOHESR) for the financial support of Fatema Rajab's PhD research.

\section{References}

[1] J. Yong, F. Chen, Q. Yang, X. Hou, Femtosecond laser controlled wettability of solid surfaces, Soft Matter, 11 (2015) 8897-8906.

[2] L. Zhang, N. Zhao, J. Xu, Fabrication and application of superhydrophilic surfaces: a review, Journal of Adhesion Science and Technology, 28 (2014) 769-790.

[3] Y.Y. Yan, N. Gao, W. Barthlott, Mimicking natural superhydrophobic surfaces and grasping the wetting process: a review on recent progress in preparing superhydrophobic surfaces, Advances in colloid and interface science, 169 (2011) 80-105.

[4] S. Wang, K. Liu, X. Yao, L. Jiang, Bioinspired surfaces with superwettability: new insight on theory, design, and applications, Chemical reviews, 115 (2015) 8230-8293.

[5] Y. Takata, S. Hidaka, M. Masuda, T. Ito, Pool boiling on a superhydrophilic surface, International Journal of Energy Research, 27 (2003) 111-119.

[6] C. Byon, Y. Nam, S.J. Kim, Y.S. Ju, Drag reduction in Stokes flows over spheres with nanostructured superhydrophilic surfaces, Journal of Applied Physics, 107 (2010) 066102.

[7] J. Gold, B. Nilsson, B. Kasemo, Microfabricated metal and oxide fibers for biological applications, Journal of Vacuum Science \& Technology A, 13 (1995) 2638-2643.

[8] A.Y. Vorobyev, C. Guo, Direct femtosecond laser surface nano/microstructuring and its applications, Laser \& Photonics Reviews, 7 (2013) 385-407. 
[9] S. Schlie, E. Fadeeva, J. Koch, A. Ngezahayo, B.N. Chichkov, Femtosecond laser fabricated spike structures for selective control of cellular behavior, Journal of biomaterials applications, 25 (2010) 217-233.

[10] M. Kreisler, W. Kohnen, C. Marinello, H. Götz, H. Duschner, B. Jansen, B. D'Hoedt, Bactericidal effect of the Er: YAG laser on dental implant surfaces: an in vitro study, Journal of periodontology, 73 (2002) 1292-1298.

[11] C. De Giorgi, V. Furlan, A.G. Demir, E. Tallarita, G. Candiani, B. Previtali, Laser micropolishing of AISI 304 stainless steel surfaces for cleanability and bacteria removal capability, Applied Surface Science, 406 (2017) 199-211.

[12] E. Fadeeva, V.K. Truong, M. Stiesch, B.N. Chichkov, R.J. Crawford, J. Wang, E.P. Ivanova, Bacterial retention on superhydrophobic titanium surfaces fabricated by femtosecond laser ablation, Langmuir, 27 (2011) 3012-3019.

[13] T. Baldacchini, J.E. Carey, M. Zhou, E. Mazur, Superhydrophobic surfaces prepared by microstructuring of silicon using a femtosecond laser, Langmuir, 22 (2006) 4917-4919.

[14] V. Zorba, E. Stratakis, M. Barberoglou, E. Spanakis, P. Tzanetakis, S.H. Anastasiadis, C. Fotakis, Biomimetic artificial surfaces quantitatively reproduce the water repellency of a lotus leaf, Advanced materials, 20 (2008) 4049-4054.

[15] J. Yong, Q. Yang, F. Chen, D. Zhang, H. Bian, Y. Ou, J. Si, G. Du, X. Hou, Stable superhydrophobic surface with hierarchical mesh-porous structure fabricated by a femtosecond laser, Applied Physics A, 111 (2013) 243-249.

[16] F. Chen, D. Zhang, Q. Yang, X. Wang, B. Dai, X. Li, X. Hao, Y. Ding, J. Si, X. Hou, Anisotropic wetting on microstrips surface fabricated by femtosecond laser, Langmuir, 27 (2010) 359-365.

[17] J. Yong, F. Chen, Q. Yang, D. Zhang, U. Farooq, G. Du, X. Hou, Bioinspired underwater superoleophobic surface with ultralow oil-adhesion achieved by femtosecond laser microfabrication, Journal of Materials Chemistry A, 2 (2014) 8790-8795.

[18] S. Wang, L. Jiang, Definition of superhydrophobic states, Advanced materials, 19 (2007) 3423-3424.

[19] J. Yong, F. Chen, Q. Yang, D. Zhang, G. Du, J. Si, F. Yun, X. Hou, Femtosecond laser weaving superhydrophobic patterned PDMS surfaces with tunable adhesion, The Journal of Physical Chemistry C, 117 (2013) 24907-24912.

[20] J. Yong, Q. Yang, F. Chen, D. Zhang, U. Farooq, G. Du, X. Hou, A simple way to achieve superhydrophobicity, controllable water adhesion, anisotropic sliding, and anisotropic wetting based on femtosecond-laser-induced line-patterned surfaces, Journal of Materials Chemistry A, 2 (2014) 5499-5507.

[21] J. Yong, F. Chen, Q. Yang, G. Du, C. Shan, H. Bian, U. Farooq, X. Hou, Bioinspired transparent underwater superoleophobic and anti-oil surfaces, Journal of Materials Chemistry A, 3 (2015) 9379-9384. 
[22] J. Yong, F. Chen, Q. Yang, U. Farooq, X. Hou, Photoinduced switchable underwater superoleophobicity-superoleophilicity on laser modified titanium surfaces, Journal of Materials Chemistry A, 3 (2015) 10703-10709.

[23] S. Moradi, S. Kamal, P. Englezos, S.G. Hatzikiriakos, Femtosecond laser irradiation of metallic surfaces: effects of laser parameters on superhydrophobicity, Nanotechnology, 24 (2013) 415302.

[24] M.V. Rukosuyev, J. Lee, S.J. Cho, G. Lim, M.B. Jun, One-step Fabrication of Superhydrophobic Hierarchical Structures by Femtosecond Laser Ablation, Applied Surface Science, (2014).

[25] D. Kam, S. Bhattacharya, J. Mazumder, Control of the wetting properties of an AISI 316L stainless steel surface by femtosecond laser-induced surface modification, Journal of Micromechanics and Microengineering, 22 (2012) 105019.

[26] V. Belaud, S. Valette, G. Stremsdoerfer, M. Bigerelle, S. Benayoun, Wettability versus roughness: Multi-scales approach, Tribology International, (2014).

[27] J. Long, L. Pan, P. Fan, D. Gong, D. Jiang, H. Zhang, L. Li, M. Zhong, Cassie-State Stability of Metallic Superhydrophobic Surfaces with Various Micro/Nanostructures Produced by a Femtosecond Laser, Langmuir, 32 (2016) 1065-1072.

[28] J. Long, P. Fan, D. Gong, D. Jiang, H. Zhang, L. Li, M. Zhong, Superhydrophobic surfaces fabricated by femtosecond laser with tunable water adhesion: from lotus leaf to rose petal, ACS applied materials \& interfaces, 7 (2015) 9858-9865.

[29] F.H. Rajab, D. Whitehead, Z. Liu, L. Li, Characteristics of hierarchical micro/nano surface structure formation generated by picosecond laser processing in water and air, Applied Physics B, 123 (2017) 282.

[30] F. Rajab, P. Benson, L. Li, K. Whitehead, Picosecond Laser Surface Micro/Nano Texturing of Stainless Steel as a Method to Reduce the Adhesion of Bacteria, in: Proceedings of LPM2017-the 18th International Symposium on Laser Precision Microfabrication, 2017.

[31] F.H. Rajab, C.M. Liauw, P.S. Benson, L. Li, K.A. Whitehead, Picosecond laser treatment production of hierarchical structured stainless steel to reduce bacterial fouling, Food and Bioproducts Processing, 109 (2018) 29-40.

[32] J. Long, P. Fan, M. Zhong, H. Zhang, Y. Xie, C. Lin, Superhydrophobic and colorful copper surfaces fabricated by picosecond laser induced periodic nanostructures, Applied Surface Science, 311 (2014) 461-467.

[33] F.H. Rajab, C.M. Liauw, P.S. Benson, L. Li, K.A. Whitehead, Production of hybrid macro/micro/nano surface structures on Ti6A14V surfaces by picosecond laser surface texturing and their antifouling characteristics, Colloids and Surfaces B: Biointerfaces, 160 (2017) 688-696.

[34] R. Jagdheesh, Fabrication of a superhydrophobic Al2O3 surface using picosecond laser pulses, Langmuir, 30 (2014) 12067-12073. 
[35] S. Razi, K. Madanipour, M. Mollabashi, Laser surface texturing of 316L stainless steel in air and water: A method for increasing hydrophilicity via direct creation of microstructures, Optics \& Laser Technology, 80 (2016) 237-246.

[36] A.M. Emelyanenko, F.M. Shagieva, A.G. Domantovsky, L.B. Boinovich, Nanosecond laser micro-and nanotexturing for the design of a superhydrophobic coating robust against long-term contact with water, cavitation, and abrasion, Applied Surface Science, 332 (2015) 513-517.

[37] L.B. Boinovich, A.M. Emelyanenko, A.D. Modestov, A.G. Domantovsky, K.A. Emelyanenko, Synergistic effect of superhydrophobicity and oxidized layers on corrosion resistance of aluminum alloy surface textured by nanosecond laser treatment, ACS applied materials \& interfaces, 7 (2015) 19500-19508.

[38] D.V. Ta, A. Dunn, T.J. Wasley, R.W. Kay, J. Stringer, P.J. Smith, C. Connaughton, J.D. Shephard, Nanosecond laser textured superhydrophobic metallic surfaces and their chemical sensing applications, Applied Surface Science, 357, Part A (2015) 248-254.

[39] F.H. Rajab, Z. Liu, L. Li, Production of stable superhydrophilic surfaces on 316L steel by simultaneous laser texturing and $\mathrm{SiO} 2$ deposition, Applied Surface Science, 427 (2018) $1135-1145$.

[40] K.-H. Leitz, B. Redlingshöfer, Y. Reg, A. Otto, M. Schmidt, Metal ablation with short and ultrashort laser pulses, Physics Procedia, 12 (2011) 230-238.

[41] Y.C. Guan, W. Zhou, Z.L. Li, H.Y. Zheng, Laser-induced microstructural development and phase evolution in magnesium alloy, Journal of Alloys and Compounds, 582 (2014) 491495.

[42] B. Liu, W. Wang, G. Jiang, X. Mei, K. Wang, J. Wang, Formation of porous structure with subspot size under the irradiation of picosecond laser pulses, Journal of Nanomaterials, 2013 (2013) 11.

[43] Y. Li, Z. Cui, W. Wang, C. Lin, H.-L. Tsai, Formation of linked nanostructure-textured mound-shaped microstructures on stainless steel surface via femtosecond laser ablation, Applied Surface Science, 324 (2015) 775-783.

[44] G. Daminelli, J. Krüger, W. Kautek, Femtosecond laser interaction with silicon under water confinement, Thin Solid Films, 467 (2004) 334-341.

[45] Z. Cheng, M. Du, H. Lai, N. Zhang, K. Sun, From petal effect to lotus effect: a facile solution immersion process for the fabrication of super-hydrophobic surfaces with controlled adhesion, Nanoscale, 5 (2013) 2776-2783.

[46] C. Cui, X. Cui, X. Ren, M. Qi, J. Hu, Y. Wang, Surface oxidation phenomenon and mechanism of AISI 304 stainless steel induced by Nd: YAG pulsed laser, Applied Surface Science, 305 (2014) 817-824.

[47] C.Y. Cui, X.G. Cui, X.D. Ren, M.J. Qi, J.D. Hu, Y.M. Wang, Surface oxidation phenomenon and mechanism of AISI 304 stainless steel induced by Nd:YAG pulsed laser, Applied Surface Science, 305 (2014) 817-824. 
